\title{
Physical Processes of Meso-Scale, Dynamic Auroral Forms
}

\author{
C. Forsyth ${ }^{1}$ • V.A. Sergeev ${ }^{2}$ - M.G. Henderson ${ }^{3}$. \\ Y. Nishimura ${ }^{4}$ B. Gallardo-Lacourt ${ }^{5,6}$
}

Received: 29 April 2019 / Accepted: 28 March 2020 / Published online: 20 April 2020

(C) The Author(s) 2020

\begin{abstract}
Meso-scale auroral forms, such as poleward boundary intensifications, streamers, omega bands, beads and giant undulations, are manifestations of dynamic processes in the magnetosphere driven, to a large part, by plasma instabilities in the magnetotail. New observations from ground- and space-based instrumentation and theoretical treatments are giving us a clearer view of some of the physical processes behind these auroral forms. However, questions remain as to how some of these observations should be interpreted, given uncertainties in mapping auroral features to locations in the magnetotatil and due to the significant overlap in the results from a variety of models of different plasma instabilities. We provide an overview of recent results in the field and seek to clarify some of the remaining questions with regards to what drives some of the largest and most dynamic auroral forms.
\end{abstract}

Keywords Meso-scale aurora · Poleward boundary intensifications · Auroral streamers · Omega bands · Torches · Auroral beads · Giant undulations · Magnetic mapping · Magnetosphere ionosphere coupling $\cdot$ Plasma instabilities $\cdot$ Magnetotail

Auroral Physics

Edited by David Knudsen, Joe Borovsky, Tomas Karlsson, Ryuho Kataoka and Noora Partmies

C. Forsyth

1 UCL Mullard Space Science Laboratory, Dorking, Surrey, UK

2 St. Petersburg State University, St. Petersburg, Russia

3 Los Alamos National Laboratory, Los Alamos, NM, USA

4 Department of Electrical and Computer Engineering and Center for Space Physics, Boston University, Boston, MA, USA

5 Department of Physics and Astronomy, University of Calgary, Calgary, Canada

6 NASA Goddard Space Flight Center, Greenbelt, MD, USA 


\section{Introduction}

Meso-scale dynamic auroral forms, with scale sizes of 10 s to 100 s of kilometres, were reported as distinct features in some of the earliest schematic diagrams of the auroral oval. Through combining observations from orbiting and ground-based imagers with in-situ measurements of the magnetosphere and remote sensing observations of the ionosphere, we have begun to understand the physical processes at the source of these auroral forms and, in some cases, the associated acceleration of particles into the ionosphere. This is coupled with a growing body of theoretical and modelling work to help understand the key physical processes that can give rise to localised enhancements of the aurora. However, mapping specific auroral features into a dynamic plasma environment that encompasses millions of cubic kilometres is not straightforward, leaving the coupling of ground and space-based observations open to interpretation. Furthermore, different theoretical and modelling frameworks give overlapping results that fit to various aspects of the observations meaning that the physical processes behind meso-scale dynamic auroral forms are, in some cases, still to be resolved.

In this chapter, we review the current understanding of the physical processes associated with auroral beads, poleward boundary intensifications, streamers, omega bands and giant undulations. For each of these, we provide current definitions, a discussion of the physical drivers and sources of these features and some of the outstanding issues with regards to understanding the magnetosphere-ionosphere coupling of these meso-scale forms. We also discuss the role that magnetic mapping has in our understanding of the coupling of meso-scale auroral forms to magnetospheric drivers. We note that most of the auroral forms discussed have been linked, in some way, to the dynamics of substorm activity, although their appearance is not exclusively during substorm times. Here, we focus on the physical drivers of these auroral forms rather than their place in the phenomenology of auroral and geomagnetic activity. For a recent discussion from the magnetospheric viewpoint, we direct readers to reviews by Keiling et al. (2013) and Sitnov et al. (2019).

\section{Poleward Boundary Intensifications}

During undisturbed, geomagnetically quiet times, the nightside auroral oval predominantly consists of relatively diffuse auroral emission covering up to $10^{\circ}$ of latitude. At times, however, the poleward edge of the nightside auroral oval can show rapid, latitudinally localised brightenings or the formation of new arcs along the poleward boundary that are now commonly refered to as Poleward Boundary Intensifications (PBIs). While observations of brightenings at the poleward edge of the auroral oval have been reported throughout studies of the meso-scale auroral morphology (e.g. Rostoker et al. 1987; de la Beaujardière et al. 1994; Henderson 1994), the terminology and investigation of PBIs as a distinct class of auroral structure largely follows on from Lyons et al. (1999).

There is some ambiguity in the literature regarding the definition of PBIs since the term is used as a general term for brightenings at or near the poleward edge of the auroral oval, with little or no distinction between different auroral morphologies. Zesta et al. (2002) suggested that three classes of PBIs could be observed: arcs that propagate across the auroral oval and are either (a) primarily north-south or (b) primarily east-west aligned arcs originating at or near the poleward boundary; or (c) arcs that remain at the poleward boundary that tend to be associated with eastward or westward moving swirls (examples of different PBIs are shown in Fig. 1). However, these distinctions are not often reported. Furthermore, auroral forms 


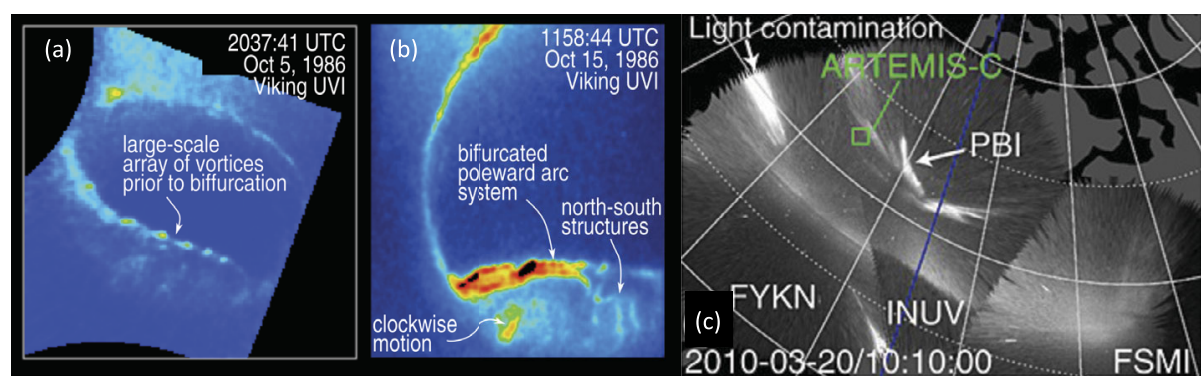

Fig. 1 Examples of poleward boundary intensifications seen in Polar (left, after Henderson 1994a), Viking (center, after Henderson et al. 1994) and THEMIS ASI data (right, after Nishimura et al. 2013c). Left: Spatially periodic bright spots (likely folds or spirals) appear on the poleward edge of the auroral oval prior to the bifurcation of the arc. Center: Example of a poleward boundary intensification associated with a bifurcation of arcs at the poleward boundary and associated equatorward ejection of streamers into the bulge. Right: Example of a quiet time PBI appearing at the poleward edge of a diffuse auroral oval

originating at the poleward boundary and extending equatorwards into the auroral oval have been described both as PBIs and auroral streamers (see Sect. 3). The point at which a PBI becomes a streamer is undefined, but, in general, streamers are considered to be auroral features that extend across the auroral oval, forming roughly north-south aligned arcs, and PBIs are transient auroral intensifications at the poleward edge of the auroral oval (Sandholt et al. 2002; Zesta et al. 2011). The lack of distinction between these different auroral forms in the literature means that there is a natural ambiguity in identifying their direct physical drivers. In the following, we concentrate on those observations at or close to the open-closed field-line boundary in order to consider the physical processes behind PBIs.

PBIs are reported at all levels of geomagnetic activity, from quiet or pre-substorm times (Lyons 2000; Kim et al. 2005; Nishimura et al. 2010b; Zou et al. 2010; Lyons et al. 2011; Zesta et al. 2011; Nishimura et al. 2013a), to during substorms (Sandholt et al. 2002; Voronkov et al. 2003; Pitkanen et al. 2013) and geomagnetic storm or storm-like events (Lyons 2000; Yue et al. 2013; Lyons et al. 2018). Global auroral imagers show enhancements of the poleward boundary after significant auroral activity which results in a double auroral oval (e.g. Henderson 1994). Much of the recent research in this field has concentrated on PBIs that extend equatorwards, rather than those that stay confined to the poleward boundary, and their potential role in the substorm cycle.

\subsection{Drivers/Causes}

Recent studies of PBIs and the physical processes that drive them have typically focussed on PBIs that result in auroral streamers by extending across the auroral oval. These are generally considered to be an auroral manifestation of localised reconnection in the magnetotail. Unlike the Near-Earth Neutral Line reconnection that occurs during substorms, which starts on closed field-lines and thus will result in brightenings within the auroral oval, the occurrence of an auroral enhancement at the poleward boundary of the aurora suggests an enhancement in reconnection occurring close to the distant neutral line. Evidence of bursts of reconnection around the time of PBIs has been provided by observations of fast plasma flows in the magnetotail plasmasheet, commonly known as bursty bulk flows or BBFs (Angelopoulos et al. 1992). BBFs are thought to be a signature of localised reconnection having happened further downtail than the observing spacecraft, with the enhanced reconnection electric field locally enhancing the convection of flux tubes through the plasma sheet. These 
signatures are often observed at times of PBI activity (Lyons et al. 1999; Zesta et al. 2000, 2006; Nishimura et al. 2010a,b; Zesta et al. 2011; Nishimura et al. 2013a,c; Pitkanen et al. 2013). However, given that the auroral oval is found on closed field-line and the poleward boundary of the auroral oval lies close to the open-closed field-line boundary, it is unlikely that observations of BBFs or reconnection signatures well within the magnetically closed plasmasheet map directly to PBIs. Notably, observations of BBFs inside of $\sim 20 \mathrm{R}_{\mathrm{E}}$ may be due to near-Earth or far-tail reconnection since the typical downtail distance of the nearEarth reconnection site is thought to be $20-30 \mathrm{R}_{\mathrm{E}}$ (Imber et al. 2011). Observations from the ARTEMIS mission at $\sim 60 \mathrm{R}_{\mathrm{E}}$ downtail show that fast plasma flows in close proximity to PBI activity (Nishimura et al. 2013c) are more likely to originate from a far-tail reconnection site. The crux of this may be the distinction between PBIs and auroral streamers combined with mapping effects: a deep-tail BBF may map to a region just inside the poleward edge of the auroral oval before it extends equatorwards and becomes an auroral streamer. This feature may be indistinguishable from any auroral features directly arising from the reconnection activity which created the BBF. Thus, while it is likely that PBIs are in some way associated with reconnection, whether they are also caused by propagating fast-plasma flows in the magnetotail remains unknown.

Observations of the plasma in the vicinity of a PBI have shown enhanced auroral precipitation, as expected for above bright aurora. Observations from the Cluster spacecraft at $3.5 \mathrm{R}_{\mathrm{E}}$ altitude enabled the time evolution of this particle population to be examined (Hull et al. 2010). These closely separated (in time) observations showed an injection of new plasmasheet plasma in concert with the PBI (see Fig. 2). This plasma initially showed a broadband energy distribution, associated with Alfvén wave acceleration, which merged with the existing plasmasheet population and evolved into a more mono-energetic population, generally associated with quasi-static electric potential drops. Similar multi-point observations by sounding rockets at lower altitude showed similar results (Mella et al. 2011; Lynch et al. 2012). Thus, the implication is that the initial formation of the PBI is driven by Alfvénically accelerated electrons, possibly arising from a reconnection site, which subsequently become quasi-statically accelerated electrons. Whether this is as a result of magnetosphereionosphere coupling and Alfvén waves 'digging out' an auroral cavity, or because the magnetospheric source of the aurora switches from an active reconnection site to the quasisteady field-aligned currents supporting a BBF in the magnetotail remains an open question.

Fast plasma flows (up to 1000s of $\mathrm{m} / \mathrm{s}$ ) in the polar cap have been observed in both coherent and incoherent scatter radar measurements prior to the activation of a PBI (Lyons et al. 2011; Bristow et al. 2016). Figure 3 shows and example event from Nishimura et al. (2010b). These have been associated with the drift of polar cap patches across the polar cap originating from reconnection on the dayside (Nishimura et al. 2014; Zou et al. 2014). Statistics have shown that $\sim 50 \%$ of PBIs can be associated with an isolated fast equatorward flow in the polar cap, with a further $30 \%$ of PBIs associated with multiple polar cap flow channels (Zou et al. 2014). The isolated flow channels tend to appear in the polar cap a few minutes prior to the activation of the PBI and the speed of the observed flows can range from $1000 \mathrm{~s} \mathrm{~m} / \mathrm{s}$ in the F-region, to up to $400 \mathrm{~m} / \mathrm{s}$ in the E-region, with E-region velocities being retarded to the ion acoustic speed. Calculations of the nightside reconnection rates at PBIs, based on the plasma flow across the OCB, show enhancements in reconnection localised to the PBI vicinity (Pitkänen et al. 2011). As such, the arrival of the fast flows at the polar cap boundary is a potential source of an enhanced electric field that drives a burst of reconnection, resulting in the PBI. However, reconnection in the far tail may also occur due to other changing conditions. Whether the reconnection event directly accelerates particles along the magnetic field to generate the auroral brightening or whether the subsequent fast magnetotail plasma flows is the source of the PBI remains unresolved. 

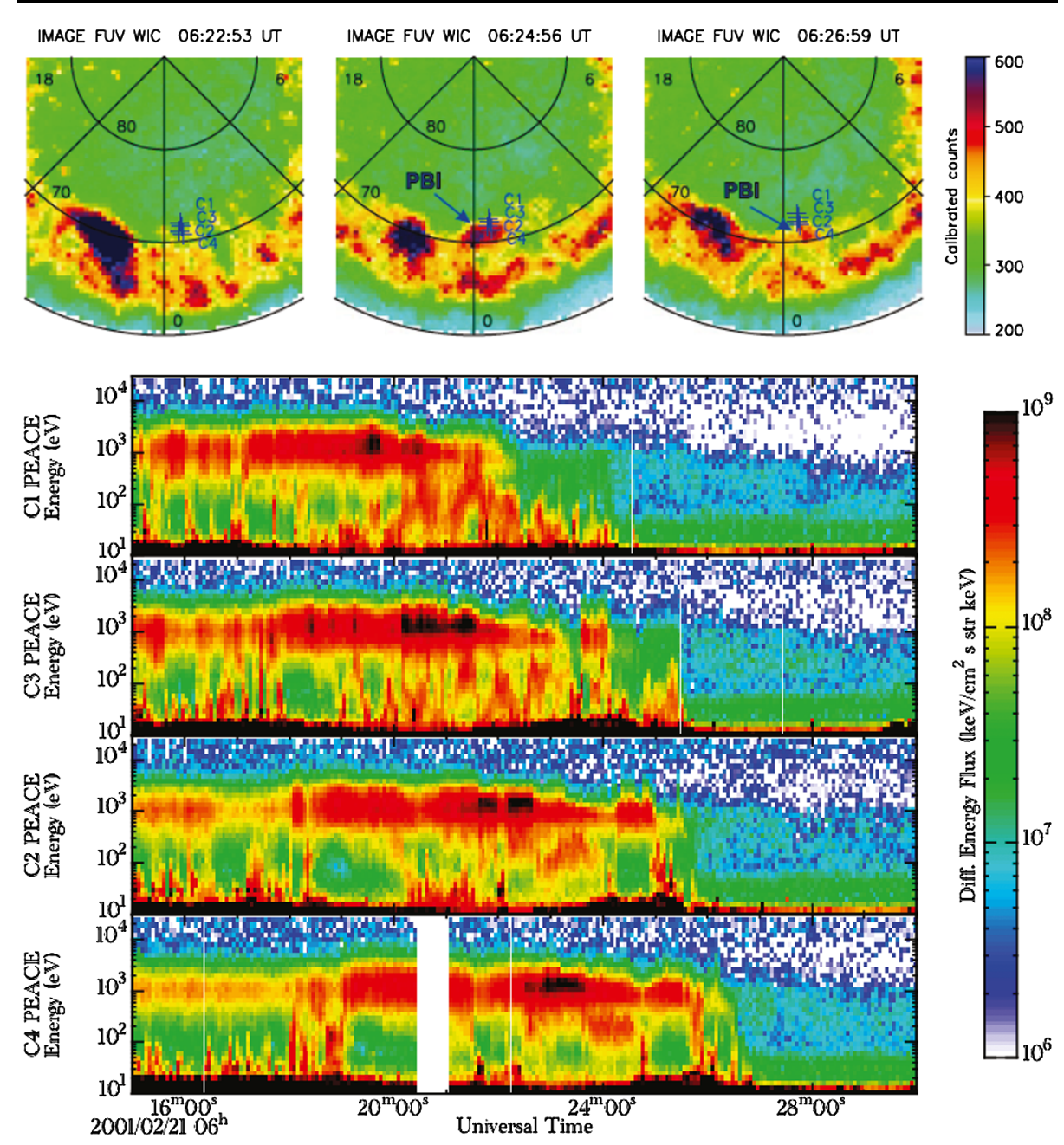

Fig. 2 Observations from IMAGE FUV-WIC and electron differential energy flux summed across all pitch angles from the Cluster PEACE instruments during a crossing of a PBI (adapted from Hull et al. 2010). Cluster 1 passed over the PBI region first (when there was no PBI), followed by Cluster 3, Cluster 2 and Cluster 4. The PEACE data shows the injection of new plasmasheet plasma (Cluster 3) next to a region of Alfvénically driven precipitation, which subsequently merges with the existing plasma and develops into a electrostatically accelerated population

One theoretical model of PBIs, based on the arrival of fast polar cap convection vortices at a conductivity boundary in the ionosphere through ionospheric polarization, suggests that the key aspect that results in the PBI is the change in ionospheric conductivity between the auroral oval and the polar cap (Ohtani et al. 2018; Ohtani and Yoshikawa 2016). In this model, the arrival of a pair of flow vortices surrounding an up-down field-aligned current pair transmitted by Alfvén waves at a gradient in the Pedersen and Hall conductivities results in enhanced field aligned currents at that boundary - currents that may be sufficiently large to result in the optical signature of a PBI (Fig. 4). Ohtani and Yoshikawa (2016) suggest that the finite conductivity of the auroral oval means that the auroral region is not shielded 

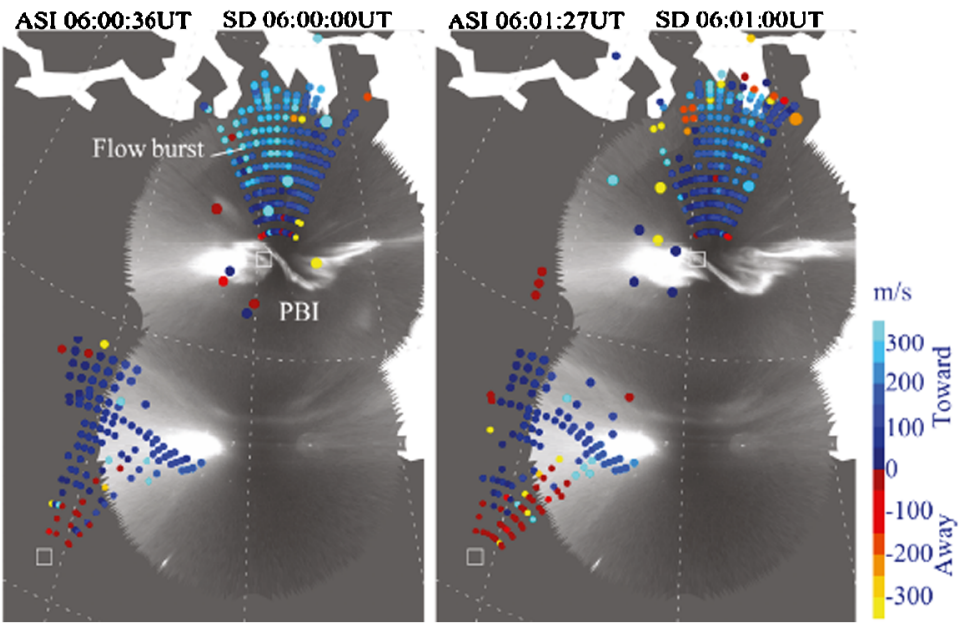

Fig. 3 Observations of ionospheric flow bursts seen in SuperDARN line-of-sight velocity data occurring in the polar cap, polewards of a PBI observed in the THEMIS ASI data (after Nishimura et al. 2010b)
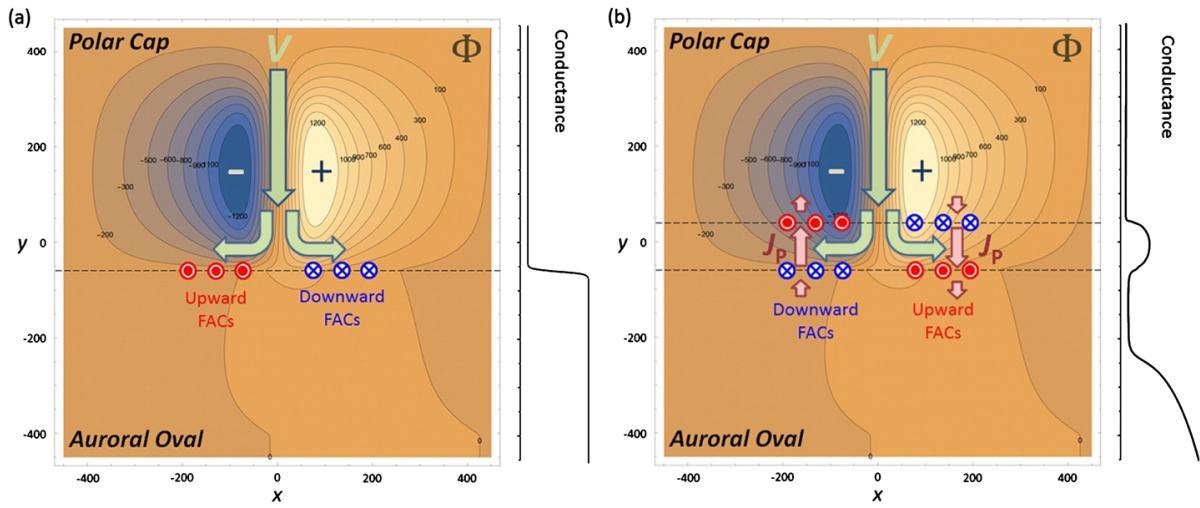

Fig. 4 From Ohtani et al. (2018): Schematic explanation of the deflection of the fast polar cap flow (light green arrow coming from the top) at (a) the step-like change of the ionospheric conductance and (b) the band of the enhanced conductance (as illustrated to the right of each panel). The electrostatic potential is shown by contours and colors, which was adopted from Fig. 5e of Ohtani and Yoshikawa (2016); although their model calculation was conducted for a step-like change of conductance, we adopted it here for both panels. The contours are squeezed out of the auroral oval (bottom half) to the polar cap (top half) because of electrostatic polarization at the poleward boundary. The vertically elongated area of dense potential contours in the middle of the polar cap corresponds to the flow channel. In panel (b) the intensities of the ionospheric Pedersen currents $\left(J_{P}\right)$ inside and outside of the conductance band are schematically shown by the arrows in magenta. See Ohtani and Yoshikawa (2016) for more details

from the incoming flow and that a finite electric field along the conductivity boundary will permit field-lines to cross into the enhanced conductivity region without the need for reconnection (and thus that processes in the magnetosphere are being driven by the ionosphere). This would appear to be in contrast with observations of reconnection signatures in the magnetotail following PBIs, however the generation of Alfvén waves by reconnection may act to enhance the effects of ionospheric polarization. 


\subsection{Implications and Outstanding Issues}

The evidence from in-situ plasma measurements of directly above a PBI and of fast plasma flows in the plasma sheet coupled with remote sensing observations of enhanced plasma flows (and hence enhanced electric fields) in the polar cap and around PBIs is strongly indicative that reconnection plays some role in the occurrence of certain forms of PBI. However, open questions remain as to the origins of PBIs and brightenings at the open-closed field-line boundary, for example: are they associated with reconnection and are brightenings that extend over significant portions of the nightside auroral oval or spatially periodic brightenings driven by reconnection or some other process? Furthermore, the question of the whether burst of reconnection at the dayside magnetopause remain cohesive in their passage through the magnetospheric lobes and lead to PBIs remains open. The modelling work by Ohtani et al. (2018), Ohtani and Yoshikawa (2016) seeks to address some of these issues by considering the interaction of plasma vortices with conductivity gradients in the ionosphere, it ignores any reconnection processes occurring in the magnetosphere. Observational studies have also shown the occurrence of dayside and nightside flow enhancements in concert with the onset of PBIs (Shi and Zesta 2014). However, the causal link between these events is yet to be conclusively demonstrated. Observations have shown that fast flows are observed typically 1-2 min before PBIs are identified (Zou et al. 2014) but often cannot discern whether the flow impinges on the OCB at the time of the PBI due to limitations in the ionospheric flow observations. Fast conjugate auroral and ionospheric observations will be key in resolving these ambiguities, since fast plasma flows need not pass through both lobes at the same speed or end up in the same location and thus PBIs without an associated plasma flow signature may be seen conjugate to a PBI with a plasma flow signature. Furthermore, the potential $\mathrm{X}$-ray imaging of reconnection events and FTEs and their passage along the magnetopause in concert with auroral observations may provide new insights (Branduardi-Raymont et al. 2012; Branduardi-Raymont and Wang 2017; Sibeck et al. 2018), but will have to be coupled with advanced modelling work, such as that offered by the Vlasiator (Palmroth et al. 2013, 2018), that can predict the lifetime and cohesion of these structures as they pass from the dayside to nightside. If these processes are the result of reconnection, understanding the physical mechanisms as well as the global and local plasma conditions that lead to localized reconnection and dictate where the reconnection outflows and structures propagate to will be critical.

A major difficulty in unravelling the physical processes behind PBIs is in having spacecraft near or at the open-closed field-line boundary in the magnetotail at the time of these brightenings. To date, we are only aware of the study by Hull et al. (2010) using a lowaltitude pass of the Cluster spacecraft to examine the changes in plasma at the poleward boundary of the auroral oval during a PBI. Observations from spacecraft in the magnetotail tend to be of plasma structures propagating through the closed plasmasheet rather which likely result from the same process that drives the PBI but are not, in themselves, the source. Furthermore, definitively determining the link between signatures in the far magnetotail and brightenings in the auroral oval requires a determination of the Alfvén velocity profile along the tail magnetic field lines such that the expected delay between in-situ measurements and their impact on the ionosphere can be accounted for.

While localised PBIs that result in auroral streamers have been widely studied, little attention has been given to PBIs that result in new arcs that remain at the poleward or the occurrence of trains of auroral swirls along this boundary. Ohtani et al. (2018) examined four events which extended longitudinally using a variety of ground- and space-based measurements and found that, in these events, the PBI was associated with an upward FAC region adjacent to a downward FAC region with a flow channel in between. They suggest that 
the Ohtani and Yoshikawa (2016) model can be adapted to reproduce the observed plasma conditions and thus that longitudinally extending PBIs are also the result of the arrival of fast plasma flows in the polar cap. However, the dynamics of the aurora during some of these events mean that the in-situ observations were not of the auroral features when they were at the poleward boundary but rather had already moved into the auroral oval. Also, a strong rotation of the structure during its mapping from equator to the ionosphere can participate in forming longitudinally extending PBIs (see Sect. 7). As such, further observations, particularly from the magnetospheric source are required to corroborate these results.

It should be noted that magnetic mapping is particularly challenging at the outer edge of the auroral oval. In this region, relatively small changes in latitude can map to vast distances downtail. As such, BBFs and fast plasma flows in the far magnetotail may map very close to the poleward boundary such as to appear as PBIs, and as such some PBIs may be driven by the physical processes associated with auroral streamers (as discussed in the following section). However, given the variety of forms of PBI, from those that extend across the oval to those that have a spatially periodic signature along the poleward boundary, it is unlikely that this explanation is universal.

\section{Auroral Streamers}

\subsection{Definitions/Examples}

As with many auroral features, streamers have been described by a number of different terms and have frequently appeared in schematics of the auroral region (e.g. Montbriand 1971; Akasofu 1976). Early studies often referred to North-South aligned auroral structures, easily distinguishable from standard east-west aligned auroral arcs by their orientation, however this alignment is no longer considered a key descriptor. Instead, a whole class of auroral features that extend across the auroral oval are now described as streamers.

Typically, auroral streamers are observed to extend out of a poleward boundary intensification (see Sect. 2) near the poleward edge of the oval or in the poleward-expanding bulge, and then propagate equatorward (Montbriand 1971; Henderson et al. 1994; Nakamura et al. 1993; Elphinstone et al. 1996; Henderson et al. 1998; Sergeev et al. 1999, 2000, 2004; Nakamura et al. 2001; Nishimura et al. 2010a; Henderson 2012). This dynamic motion away from their origin and (commonly) toward the equatorward boundary are now considered key aspects and implies that their magnetospheric source propagates from close to the open-closed field line boundary toward the inner magnetosphere. Figure 5 shows an example of several streamers observed by the Polar UVI instrument (adapted from Sergeev 2005). The propagation from the poleward to equator edge of aurora can be seen for the features labelled $B$, $C, D$ and $E$. Their orientation may be north-south (structure A), or more inclined (structures B-E), sometimes being purely east-west in a particular local time sector (see, e.g., structure D between 20 and $24 \mathrm{~h}$ MLT). Frequently, E-W aligned streamers are an extension of N-S streamers that turn azimuthally following meso-scale convection pattern after approaching the equatorward boundary of the auroral oval (Henderson et al. 1994; Kauristie et al. 2003; Nishimura et al. 2010a). In the duskside convection cell, the azimuthal turning of streamers appear as a tracer of streamlines along the Harang flow shear with a clockwise loop opening to the west. Those streamers are called Harang aurora.

The identification and tracking of auroral streamers from ground or space-based imagers is non-trivial. In global auroral images, streamers are seen inside the poleward-expanding auroral bulge in the substorm expansion/recovery phases or during continuous geomagnetic 


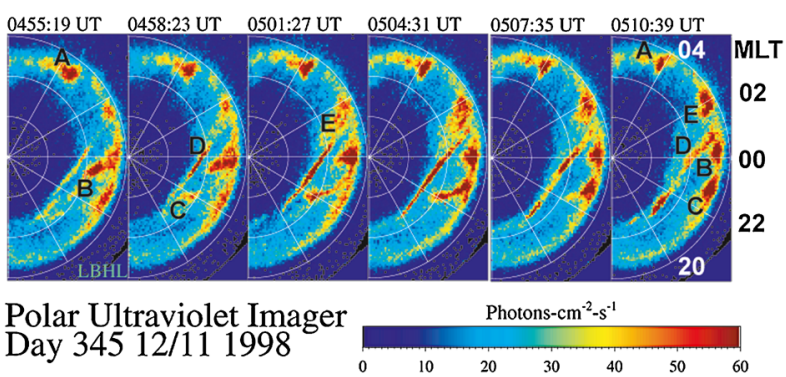

Fig. 5 Example of multiple auroral streamers. Development of four auroral streamers (B, C, D, E which eventually formed the bright patches B, C, E) and the eastward drift of bright patch A (created by previous streamer) as observed by Polar UVI imager during a steady convection event on December 11, 1998. The coordinates are AACGM - MLT (after Sergeev et al. 2005)

activity, in both cases in the so-called double auroral oval configuration (e.g. Rostoker et al. 1987; Henderson et al. 1994, 1998; Forsyth et al. 2008). However, the limited spatial and temporal resolution of global imagers (typically $\sim 100 \mathrm{~km}$ ) means that the propagation may be missed, especially when the width of the auroral oval is small, and a streamer or streamers could be identified simply as a localised auroral enhancement. From ground-based imagers, $\mathrm{N}-\mathrm{S}$ streamers can be seen without PBIs when PBIs are poleward of available imager coverage, and imagers may only detect the E-W segment of streamers when the N-S segment is outside coverage, which may be confused with more typical E-W aligned arcs.

Ionospheric convection signatures as well as field-aligned currents associated with the streamers have been examined using ground-based and in-situ measurements. The streamer itself is associated with a narrow region of intense $\left(2-25 \mu \mathrm{A} / \mathrm{m}^{2}\right)$ upward field-aligned current, with a larger, more diffuse region of weaker downward field-aligned current observed to the dawnward side, both of which can be deconvolved from ground magnetometer data or observed by spacecraft (Amm et al. 1999; Sergeev et al. 2004; Nakamura et al. 2005; Forsyth et al. 2008). Enhanced equatorward convection electric fields resulting in plasma velocities of $>1 \mathrm{~km} / \mathrm{s}$ and a potential drop of up to $13 \mathrm{kV}$ across the flow channel have also been observed in association with auroral streamers (Amm and Kauristie 2002; Sergeev et al. 2004; Nakamura et al. 2005; Amm et al. 2011; Pitkänen et al. 2011; Shi et al. 2012; GallardoLacourt et al. 2014b). The equatorward flow is observed between the upward and downward field-aligned currents, with weaker poleward flows observed outside of the current system. Recent statistical study by Gallardo-Lacourt et al. (2014b) confirmed that in $\sim 90 \%$ of 135 studied streamers the SuperDARN radars detected an enhanced equatorward flow with an average width of $75 \mathrm{~km}$ offset by $58 \mathrm{~km}$ to the east from the narrow optical streamer.

The entire ionospheric field-aligned current pattern corresponds to the $\sim 1 \mathrm{hr}$ MLT-wide equatorward flow channel with narrow downward and upward currents on its flanks. Observations by over-flying spacecraft have shown that a narrow region of monoenergetic electron precipitation is responsible for auroral signature of the streamer and coincides with the upward FAC on the dusk flank of the flow channel (Sergeev et al. 2004, see Fig. 6). Mapped into the equatorial magnetotail the streamer width is estimated to be $1.5-2.6 \mathrm{R}_{\mathrm{E}}$ (GallardoLacourt et al. 2014b) in keeping with the observed size of BBFs (e.g. Nakamura et al. 2004). This picture is valid for the poleward part of the streamer where, in addition, the return (poleward) flows are observed on flanks of the main flow channel in $10 \%$ of events (see also a case study by Pitkänen et al. 2011; Juusola et al. 2013; Aikio et al. 2018). When approaching the equatorward region where the streamer deforms, its properties change as described below. 


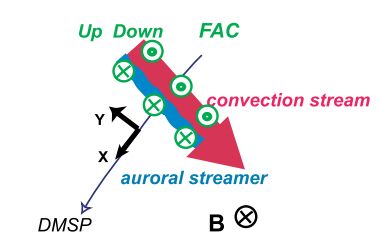

in Southern hemisphere

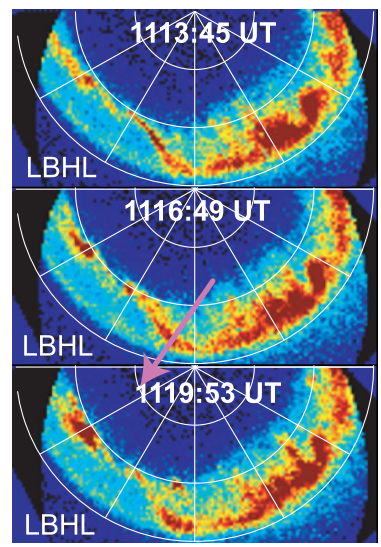

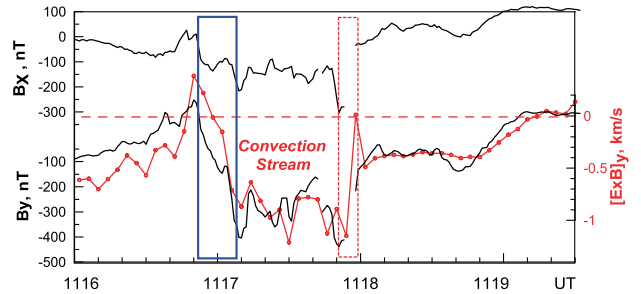

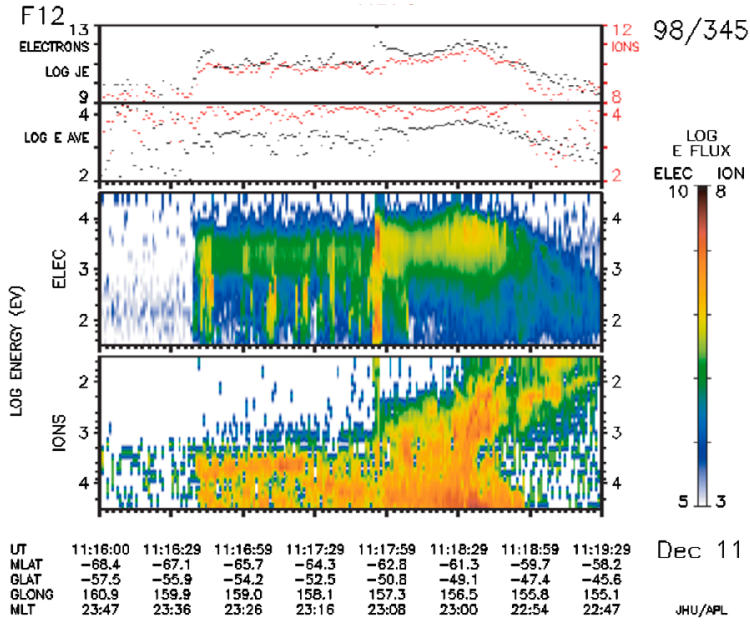

Fig. 6 Precipitation, convection and FAC patterns of auroral streamer observed by DMSP in the Southern hemisphere (adapted from Sergeev et al. 2004). Polar UVI observations in the northern hemisphere of the auroral streamer with conjugate DMSP traversal above the streamer (indicated by pink arrow) together with the schematic of observed patterns (as viewed from below in the southern hemisphere) are shown on the left panels. DMSP observations on right panels include particle spectrogram (bottom) together with horizontal magnetic field variations (black) and convection velocity changes (red line, corresponds to the flow component nearly aligned along the streamer). The entire pattern corresponds to the $\sim 1 \mathrm{hr}$ MLT-wide equatorward flow channel with narrow downward (DFAC) and upward (UFAC) on its flank; narrow streamer precipitation coincides with the UFAC and located on the dusk flank of the flow channel

\subsection{Drivers/Causes}

Correlation has been established between appearance and location of auroral streamers and fast plasma jets (or BBFs) observed in-situ in the equatorial magnetotail (e.g., Henderson et al. 1998; Sergeev et al. 1999, 2000, 2004; Fairfield et al. 1999; Ieda et al. 2008; Nakamura et al. 2001; Zesta et al. 2000, 2002, 2006; Grocott et al. 2004 Forsyth et al. 2008; Pitkänen et al. 2011; Zou et al. 2010; Juusola et al. 2013). Various aspects of their relationships are illustrated in Fig. 7 (after Sergeev et al. 2000). In this event, during development of the streamers recorded by Polar UVI imager (image on the right), three magnetospheric spacecraft (Interball-Auroral, Geotail and LANL geostationary spacecraft) were magnetically conjugate to the streamer and registered different manifestations of flow channel development. Geotail (at $r \sim 26 \mathrm{R}_{\mathrm{E}}$, blue point on the sketch) detected the flow channel directly in the plasma sheet by observing two enhancements of earthward flow and BZ accompanied by plasma pressure decreases, which are basic signatures of flow channel. Interball-Auroral (at $\sim 2 \mathrm{R}_{\mathrm{E}}$ altitude above the ionosphere, red point on sketch) recorded two intense timeof-flight dispersed injections of accelerated protons into the streamer-related magnetic flux tube, from which an inferred injection distance $\left(r \sim 40 \mathrm{R}_{\mathrm{E}}\right.$ in both cases) and injection time 


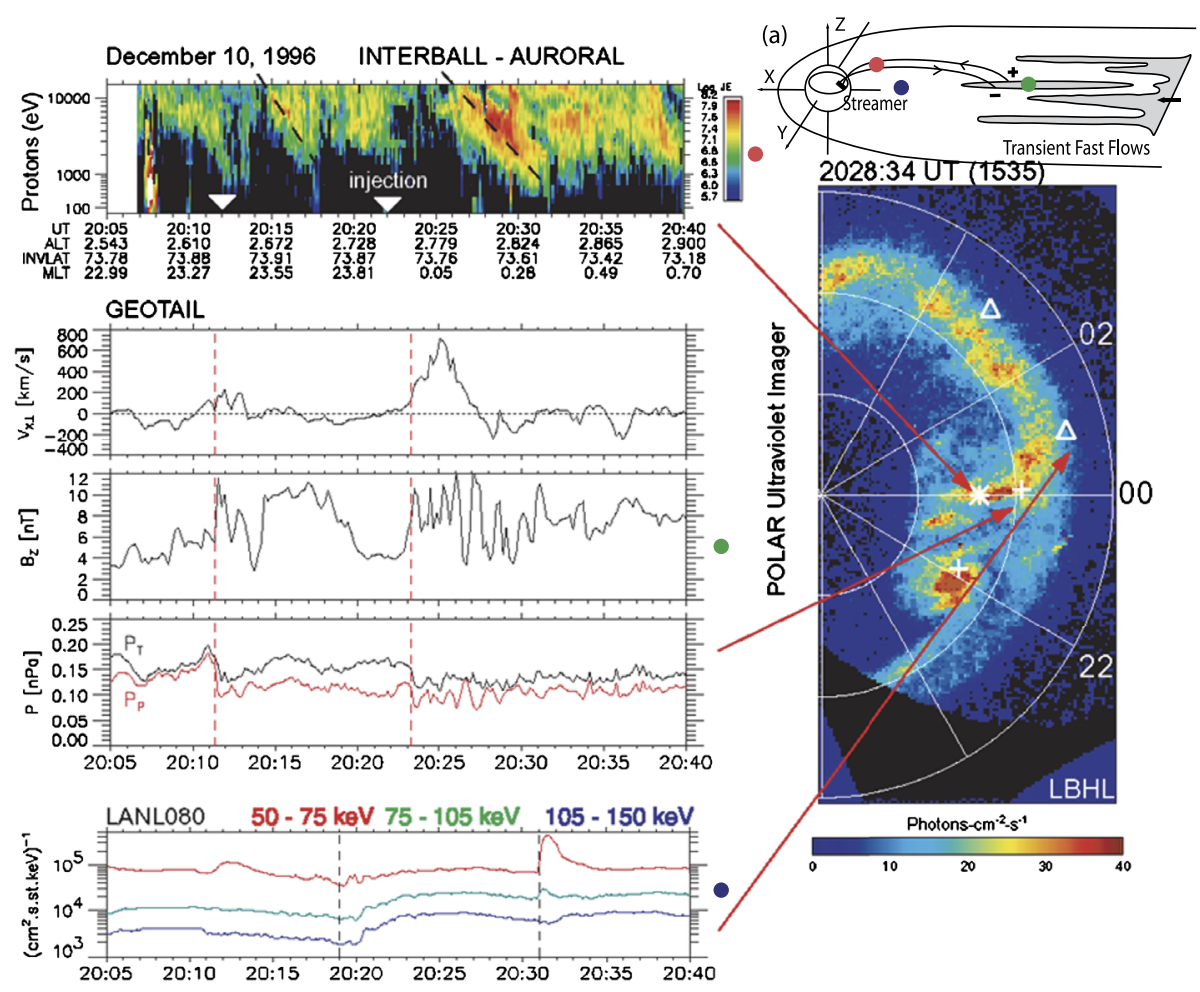

Fig. 7 Left: Magnetotail observations of 3 spacecraft, including: proton spectrogram at Interball (top); VxBz and plasma (and total) pressure observed by Geotail (center panel); energetic particle flux at LANL-080 geostationary spacecraft (bottom). Right panels show: a sketch of flow channels and their field-aligned currents with colored points indicating spacecraft locations (top); Polar UVI image showing the auroral streamer with mapped spacecraft locations indicated by asterisk (Interball), cross (Geotail) and triangle (LANL). (Adapted from Sergeev et al. 2000)

(white triangles in Fig. 11) are found, with both being in close agreement with commencements of Geotail flow channel events. At geosynchronous orbit, the LANL spacecraft (green point) observed two energetic electron flux increases with a $\sim 8$ min time delay after Geotail, suggesting that the flow channel injected energized plasma into the inner magnetosphere.

As discussed further in Sect. 7, mapping along the magnetic field lines using available magnetospheric models is rather uncertain, especially for the mapping in the meridional plane (latitude versus distance downtail). However magnetic mapping in azimuthal direction is less dependent on which model is used, and a distinct correspondence between Y-location of the flow channel and reconnection signatures in the plasma sheet and the magnetic local time of auroral streamer from global auroral images has been established (Nakamura et al. 2001). Typically, the mapped location of the magnetospheric signature is east of the auroral streamer, however Nakamura et al. (2001) showed that when the magnetospheric spacecraft crossed through the dusk flank of a BBF, there was better agreement between the streamer and mapped location. This helped to establish that streamers were mapped to the dusk flank of the flow channel ( $\triangle$ MLT $\sim 0$ for positive values $\alpha_{\mathrm{N}}$ ) whereas the dawn flank crossings of the flow channel (negative values $\alpha_{\mathrm{N}}$ ) have $\Delta$ MLT $\sim 1-1.5$, implying that the entire width of streamer mapping is about $1 \mathrm{~h}$ MLT. This width is consistent with in-situ determinations of BBF cross-tail width of 2-4 $\mathrm{R}_{\mathrm{E}}$, obtained from statistical studies (Nakamura et al. 2004). 
(a)
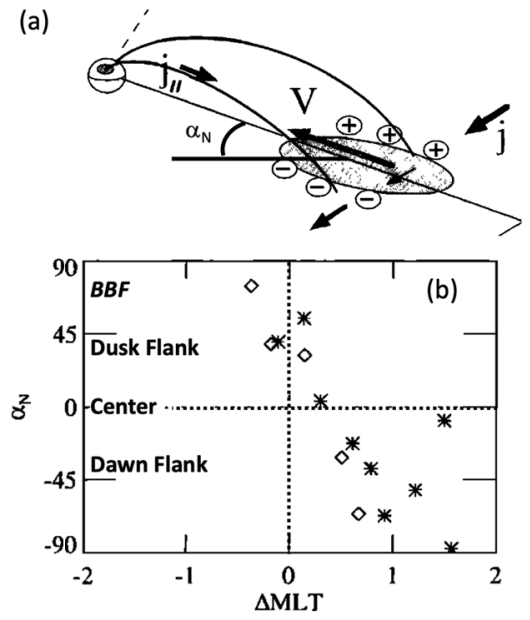

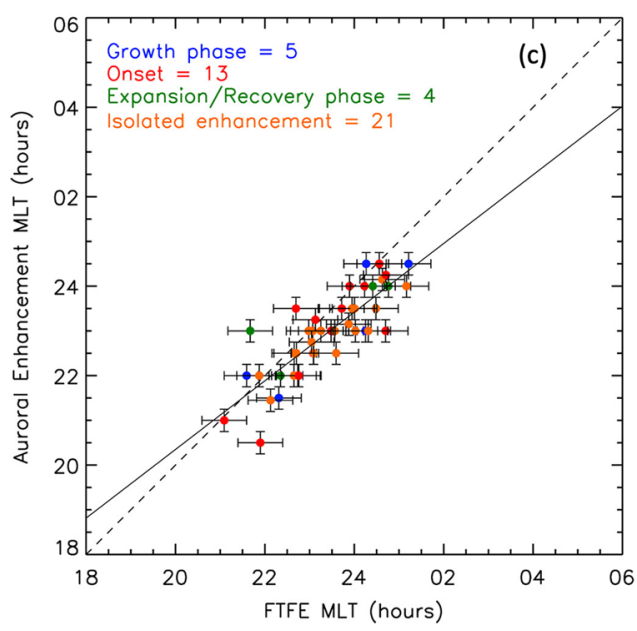

Fig. 8 (a) Scheme of fast flow channel (BBF), and, (b) - relationship of MLT difference between BBF ionospheric footpoint and streamer $\left(\mathrm{DMLT}=\mathrm{MLT}_{\mathrm{msph}}-\mathrm{MLT}_{\mathrm{isph}}\right)$ against the angle $a_{N}$ characterizing which BBF side was crossed by spacecraft (both after Nakamura et al. 2001). Diamonds (or crosses) indicate the streamers (or localized brightenings) observed in the ionosphere. (c) MLT comparison of fast tailward flows (FTFE) footpoint and auroral brightenings from Case et al. (2017); red ellipse helps to see that $\sim 1 \mathrm{~h}$ MLT-wide points cloud lay under the diagonal (shown by dashed black line) indicating a systematic dawnward shift of FTFE footpoints from their related optical effects. See text for discussion

Both conclusions (width and streamer location on the dusk side of the flow channel) are consistent with the characteristics of ionospheric pattern.

The well-developed auroral streamers are not as frequently observed in global UV images as the BBFs are observed in the plasma sheet. For example, Nakamura et al. (2001) found that more than half of the signatures of BBFs were localized auroral brightenings (marked by asterisks in Fig. 8b), rather than streamers (marked by diamonds). However, the spatial ordering of both streamers and localized brightenings with respect to the flow channel is the same, suggesting that auroral brightenings are also associated with the upward FAC region on the duskward flank of the BBF. Other studies have shown similar correspondence and MLT offsets between auroral enhancements and fast flows or reconnection signatures in the magnetotail (Ieda et al. 2001, 2008; Case et al. 2017), but did not explicitly examine auroral streamers. These results may reflect an observation bias, with global auroral imagers unable to resolve the detail of narrow auroral streamers, particularly when the auroral oval is relatively narrow.

Case studies of auroral streamers based on global auroral images are almost exclusively from intervals with a wide 'double oval' configuration, when the magnetic flux in the plasma sheet is large. In contrast, ground-based imaging with higher spatial resolution can detect streamers in a thin auroral oval during the substorm growth phase, where the oval latitudinal thickness can reduce down to a few degrees (Nishimura et al. 2011). It is also important to note that growth-phase and quiet-time streamers are dimmer by an order of magnitude and have little ground magnetic field perturbations and slower motion (c.f., Nishimura et al. 2013a,b). They may also only be apparent within a given wavelength range which can become washed out in white light images (Kepko et al. 2009). Their different properties may be related to their origins in the magnetotail, as well as to different energies of precipitating electrons and resulting Hall conductivity. Growth-phase and quiet-time streamers have been associated with Earthward flows at the lunar orbit, suggesting a distant neutral line origin 
(Xing et al. 2010). The brightest streamers occur during the substorm expansion-phase and those streamers are associated with tailward flows at the lunar orbit, indicating near-Earth neutral line origin. BBFs originating closer to the Earth generally have lower entropy and involve larger acceleration, giving brighter streamers. However, the fact that non-streamer auroral signatures are reported conjugate to magnetotail reconnection signatures may suggest that auroral streamers are part of a wider class of reconnection flow related auroral brightenings.

In combination, all these results support the plasma sheet fast flow channel (BBF) as the origin of ionospheric manifestations of the auroral streamers. BBFs are natural products of magnetic reconnection pulses in the magnetotail, which are localized in the cross-tail direction. On the Earthward side of the reconnection X-line, the fast (initially Alfvénic) Earthward flow forms on the closed field lines connected to the ionosphere. These plasma tubes are underpopulated and carry the enhanced $\mathrm{Bz}$ compared to the ambient media (which are signatures of plasma bubbles), which causes their electric polarization shown in Fig. 7 and supports the interchange-type Earthward motion of the bubble, although it should be noted that under certain magnetotail configurations, in which there is a significant Bz maximum in the middle tail, the interchange instability can occur prior to the onset of reconnection (e.g., Pritchett 2005; Sitnov et al. 2013; Birn et al. 2018). A natural consequence of the polarized flow channel is the formation of Region 1-type field-aligned currents on its flanks, with upward (or downward) FAC delineating the dusk (or dawn) flank. Such plasma/FAC pattern is invariably reproduced in the RCM simulations (Yang et al. 2011) and MHD simulations of localized reconnection and plasma bubble motion (see, e.g., Birn et al. 2004; Birn and Hesse 2013) whose results are consistent with in situ spacecraft observations of BBF in the Earth's magnetotail (e.g. Sergeev et al. 2012; Wiltberger et al. 2015). The observed upward FAC region will require the acceleration of electrons along the magnetic field (Knight 1973), consistent with observed monoenergetic spectra in the auroral streamer (e.g., Fig. 6). It should be noted that not all streamers result from monoenergetic precipitation. Multi-wavelength observations of streamers have shown that some streamers appear as diffuse aurora in the $630 \mathrm{~nm}$ band, with the particle flux responsible for the auroral emission most likely coming from enhanced scattering of relatively cool plasma from the plasma sheet or an Alfvénic acceleration process (Kepko et al. 2009). This does not discount plasma sheet fast flows as a source of this precipitation. In fact, recent observations have shown that whistler-mode waves observed in fast plasma flows are the dominant scattering process and may enhance diffuse aurora (Wendel et al. 2019).

\subsection{Implications and Outstanding Questions}

Auroral streamers are a key indicator of magnetospheric dynamics and the coupling between the magnetosphere and the ionosphere. They are linked with Poleward Boundary Intensifications (Sect. 2) and omega band activity (Sect. 4) and their motion across the auroral oval is linked to the mapping and motion of readily identifiable plasma structures in the magnetosphere. However, questions remain with regards to streamer lifetimes and, in particular, what happens as their source flows enter the inner magnetosphere.

Observations of auroral streamers show that they can turn from N-S aligned arcs to E-W aligned arcs or rotate to follow convection around the Harang discontinuity as they approach the equatorward edge of the auroral oval, however the motion and evolution of the magnetospheric driver at this time remains poorly investigated even though some interesting material is already available. RCM and MHD simulations of flow channels approaching the inner magnetosphere show a prominent (about a factor 2) increase of plasma pressure ahead 
of the dipolarization front near its stopping point (Yang et al. 2011; Birn and Hesse 2013), which impacts on the pressure distribution across the magnetotail as well as the supporting field-aligned currents (Shiokawa et al. 1998). Supporting in-situ observations from the THEMIS spacecraft have been reported (Yao et al. 2013; Sergeev et al. 2014).

In the case of multiple streamers, Nishimura et al. (2011) observed intensifications of previous equatorward arcs when streamers approached close to but did not immediately reach those arcs, instead rotating towards the azimuthal direction. Such streamer rotation from roughly NS direction toward oval-aligned direction, reminiscent of the convection streamline, is very typical (Nishimura et al. 2010b). On occasion, this rotation has been associated with the reformation of convection pattern in this region as reflected in the change of equivalent current pattern (Kauristie et al. 2003). Furthermore, some streamers have been observed to split as they approach the equatorward edge of the auroral oval, which may be in indication that some form of ballooning instability is disrupting the plasma flow channel in the magnetosphere (Pritchett and Coroniti 2013; Pritchett et al. 2014).

While the link between streamers and fast plasma flows in the magnetotail has been extensively explored and reported, a number of outstanding issues remain. Firstly, individual flow bursts are associated with an ion-scale dipolarization front which carries a strong fieldaligned current (Hwang et al. 2011; Liu et al. 2013; Sun et al. 2013; Zhou et al. 2013), however the corresponding narrow auroral feature is yet to be identified. Furthermore, the magnetospheric plasma flow is a transient feature, whereas streamers can be observed for $10 \mathrm{~min}$ or more. The streamer may be the footpoint of a channel of an under-populated fast flows, as seen in some simulations (e.g. Wiltberger et al. 2015), however how these flow channels persist and support sufficient field-aligned current to result in a bright auroral footprint, particularly in the flow braking region where the contrast between the plasma conditions in the flow and the surrounding plasma is diminished, remains an open question.

Some auroral streamers are seen disconnected from the poleward boundary of the aurora oval, as can be seen in Fig. 5 and 6. A number of explanations may be plausible. Firstly, if the fast plasma flow and streamer are the result of a burst reconnection in the magnetotail, the plasma flow will continue to exist after the reconnection ceases and thus the streamer would be disconnected from the poleward boundary. Alternatively, disconnected streamers may indicate that some streamers do not originate from PBIs but instead arise due to reconnection on closed field-lines within the plasma sheet. Furthermore, the strength of the FACs at the edge of the fast plasma flows, which is related to the brightness of the auroral signature, may vary with time or distance along the magnetotail. We note, in particular, that the auroral luminosity in the red-line aurora reported by Kepko et al. (2009) was weak and may be missed in white-light imagers, which predominantly observe green-line emissions. This raises questions as to the sources of streamers with respect to PBIs and the response of the auroral emission to the evolution of the fast plasma flows as they propagate through the magnetotail. Understanding these differences is critical in understanding the source of streamers and their potential implications in the wider dynamics of the magnetosphere.

The arrival of streamers at the equatorward edge of the auroral oval in the premidnight sector has been shown to be correlated with enhancements in subauroral (westward) convection events (Gallardo-Lacourt et al. 2017) which may play a role in the excitation of giant undulations (Sect. 6). The arrival of the streamer at the equatorward boundary also coincides with enhancements in the proton aurora at subauroral latitudes (Nishimura et al. 2014) and can excite omega band activity (Henderson et al. 2002; Sergeev et al. 2005; Henderson 2012; see Sect. 5). This indicates a prompt (on minutes scale) modification of inner magnetosphere convection by the intrusion of a magnetospheric flow channel. Furthermore, energetic particle injections at geosynchronous orbit have been observed in concert with 
streamers approaching the equatorward boundary of the auroral oval (Henderson et al. 1998; Sergeev et al. 2000). Lyons et al. (2002) reported similar results but describes the auroral activity as equatorward extending, which may also be described as streamers. These findings are consistent with the results of global RCM simulations by Yang et al. (2015) that show that flow bursts play an important role in the populating the ring current, providing as much as 20 to $60 \%$ of ion injections into the ring current during magnetic storms. While recent studies have shown links between injections in the inner magnetosphere and flow bursts further out (Runov et al. 2009; Gabrielse et al. 2012), other studies have shown that fast plasma flows are typically deflected around the Earth outside of geosynchronous orbit (Juusola et al. 2011; McPherron et al. 2011). Understanding how, when and why the magnetotail counterpart of streamers affects the inner magnetosphere, and how any feedback from the auroral enhancements impacts upon this, remains an open question.

\section{Omega Band and Torches}

\subsection{Definitions}

The omega band is a description of a dynamic diffuse auroral arc predominantly seen towards the end of substorm expansion phases or during substorm recovery phases. Although no longer commonly used, the term "band" was used by Akasofu and Kimball (1964) to describe an "arc" that has multiple folds in it and "drapery" as more active and complex displays of arcs containing rays, folds and loops. An omega band is a folded auroral arc in which the undulations of the poleward edge resemble a train of inverted capital greek letter omegas (Akasofu and Kimball 1964). These undulations are observed to move eastwards. The curved parts of the drifting inverted omegas are rooted to the equatorward regions of an expanded oval with the tongues of luminosity pointing polewards towards the more active expanded substorm bulge or double oval configuration. Along with the diffuse auroral emissions, the equatorward parts of the omega structures tend to merge together to form a wavy band of luminosity that dramatically contributes to the lower latitude component of the double oval distribution.

When a poleward-protruding tongue of luminosity (one of the legs of the omega) extends dramatically towards the poleward active arc system, the feature is referred to as an "auroral torch". These structures are most prominent at the western edge of omega band trains but can form anywhere along an already existing train. Dramatic examples of auroral torch structures can be seen in the DMSP imagery examined by Akasofu (1974) (see Fig. 9). "Brush-like" torches are wider than the "filamentary torch" and tend to appear off the equatorward auroral band, whereas the "filamentary torch" forms can connect all the way up into the high-latitude poleward arcs and are now more commonly referred to as auroral streamers (see Sect. 3).

High time resolution auroral imaging studies have revealed that auroral torch structures are "activity centers" for pulsating aurora (Oguti 1981; Tagirov 1993), with a complex "streaming type" of pulsation occurring within auroral torches inside a boundary enveloped by a non-pulsating peripheral region (see Fig. 10). The streaming striations have periods from 5-10 s and apparent speeds of 30-100 km/s. Equatorward of the streaming striations, diffuse patches are observed that display either quasi-periodic streaming and/or longitudinal "flooding motions" (patches brightening beyond their boundaries and enveloping neighboring patches). In addition, the intense energetic electron precipitation that accompanies omega band displays has distinctly different spectral characteristics from those found in 
Fig. 9 A variety of auroral torches seen in DMSP imagery. The "filamentary torches" described by Akasofu were thought to protrude into the polar cap. Today, we would call these "auroral streamers" and they are known to originate at the poleward boundary arc system. (Adapted from Akasofu 1974)
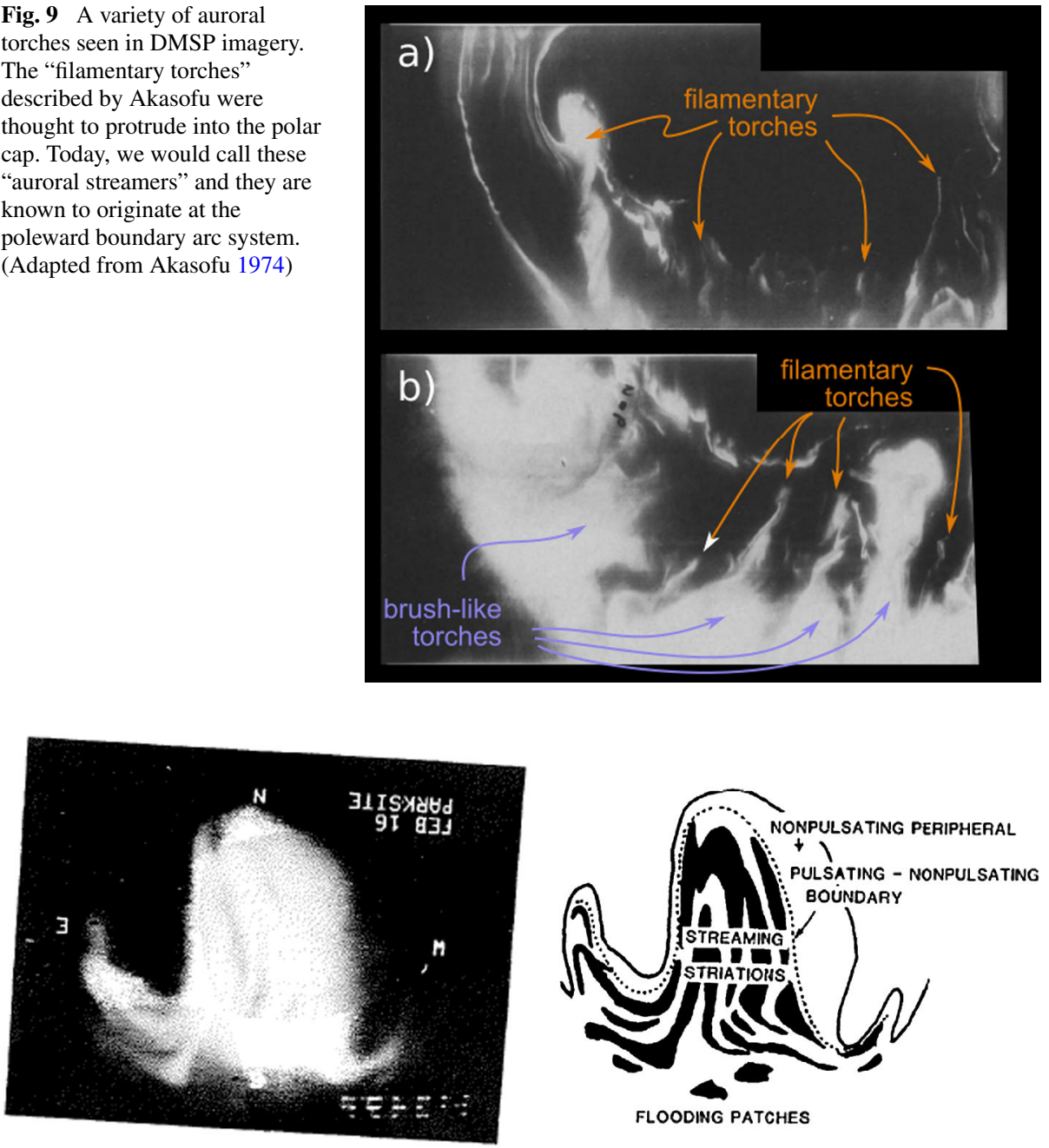

Fig. 10 An auroral torch is an activity center for pulsating aurora. (Adapted from Oguti 1981)

evening sector arcs or westward travelling surge type forms that are associated with substorm onset and expansion phase activity (e.g. Opgenoorth et al. 1994). The flux of low energy $(\sim<1-2 \mathrm{keV})$ and high energy $(>10-40 \mathrm{keV})$ electrons is higher above omega bands than for intense morning sector precipitation. Thus, the formation of torches results from the enhancement of auroral activity and may be related to the acceleration of particles in the magnetosphere and irregularities in the cold plasma (Oguti 1981).

On the ground, omega bands are associated with large-scale Ps6 magnetic pulsations that have periods of 10-30 min (Ps6 are a subclass of Pi3 pulsations) (Saito 1978). Opgenoorth et al. (1983) demonstrated that these pulsations are causally related to paired upward and downward field-aligned current (FAC) structures in which the bright tongues are associated with upward FAC and the dark voids are associated with downward FAC (also see Wild et al. 2000.) The enhanced electron fluxes also lead to low Pedersen/Hall conductivity ratios in this region and an overall lower altitude of the peak Hall conductivity layer. 


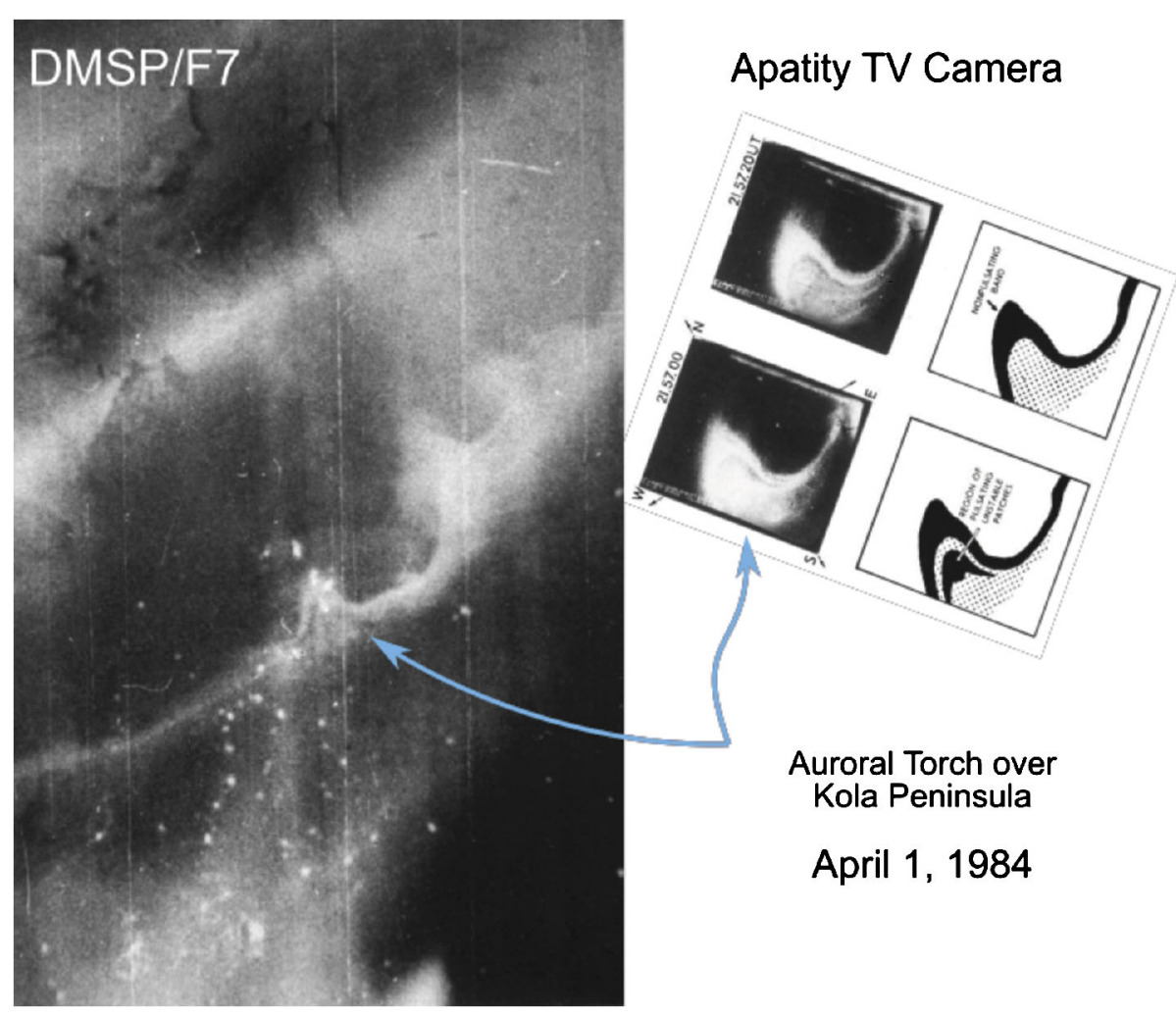

Fig. 11 High-time resolution ground-based imaging of an auroral troch-like structure observed over Apatity on April 1, 1984. Left: DMSP/F7 image showing torch/omega-band forms. Right: Apatity TV camera shows details of pulsating forms within the western-most torch. (Adapted from Tagirov 1993)

Omega bands have been typically thought to occur in the morning sector during the recovery phase of substorms (Akasofu 1974; Opgenoorth et al. 1994) or during periods with an active double oval that often develop out of substorms that remain continuously driven or from a reactivation of a quiescent high latitude arc system (i.e. Steady Magnetospheric Convection Type of activity). However, a recent statistical study that combined automated and manual detection algorithms shows that while omega band occurrence peaks in 02-03 MLT sector, approximately $10 \%$ of the observed omega bands appeared in the pre-midnight sectors. Furthermore, only two thirds of the observed omega bands appeared in the recovery phase, with the remaining third tending to be observed during substorm expansion phases (Partamies et al. 2017). Interestingly, omega bands tended to be associated with times of greater than average geomagnetic activity, with the IL index (AL index from the IMAGE magnetometer array) being $-100 \mathrm{nT}$ smaller than for all substorm, Dst reaching nearly $-50 \mathrm{nT}$ indicating storm-like activity, and Kp averaging 4.

\subsection{Drivers/Causes}

Mapping auroral omega bands observed in the ionosphere to their source locations in the magnetosphere is key to understanding their generation. In terms of contextual mapping, as distortions near the poleward regions of the diffuse auroral region and well away from the 
active high-latitude aurorae, they most likely have a near-Earth source region (Opgenoorth et al. 1994). In addition, several studies using empirical magnetic field models to map the structures to the equatorial plane (Min-B surface) concluded that omega bands map to regions quite close to the Earth $\left(<10 \mathrm{R}_{\mathrm{E}}\right)$ and thus that some type of instability in the inner magnetosphere is responsible for the development of the distortions (Pulkkinen et al. 1991; Tagirov 1993; Opgenoorth et al. 1994; Jorgensen et al. 1999). Nevertheless, several past studies incorrectly placed the omega band at the polar cap boundary rather than the edge of the diffuse aurora which led them to surmise that the distortions mapped to the open/closed boundary and the plasma sheet boundary layer on the nightside (e.g. Akasofu et el. 1971).

Due to the wave-like nature of omega bands combined with the pronounced eastward drift, many studies have invoked Kelvin-Helmholtz types of instabilities as an explanation (Rostoker and Samson 1984; Lyons and Walterscheid 1985; Buchert et al. 1990; Connors and Rostoker 1993; Wild et al. 2000). The growth rate of the KHI maximises for a velocity shear in the direction of the wave growth and perpendicular to the magnetic field (Southwood 1968; Walker 1981), resulting in large-scale, low frequency waves. Identifying the region where this occurs has proved trickier. Rostoker and Samson (1984) suggested that such conditions could arise between the low-latitude boundary layer and the surrounding plasma, potentially generating omega bands, the westward travelling surge and dayside Pc pulsations. Other mechanisms place the velocity shear at the inner edge of the plasma sheet (e.g. Connors and Rostoker 1993). Subsequent observations have shown that the edge of the diffuse aurora in omega bands corresponds to the boundary between the Region 1 and Region 2 current systems, mapping further downtail than the LLBL (Wild et al. 2011). Strong shear flows have been observed by low-altitude spacecraft in this region during the occurrence of omega bands (Liu et al. 2018), however these shear flows are a ubiquitous feature of the boundary between the R1 and R2 currents (Jiang et al. 2015; Archer et al. 2017) and as such, the occurrence of a shear flow does not appear to be sufficient to generate an omega band. This region is also generally stable to the KHI particularly when the coupling to the ionosphere is considered but may be unstable to the hybrid Kelvin-Helmholtz/Rayleigh Taylor Instability (Yamamoto 2009, 2011). However, none of these mechanisms, by themselves, appear to be consistent with the observation that omega band waveforms are often irregular in nature and it seems implausible that the KHI can produce the very pronounced torch-like structures that are commonly observed to extend far toward the poleward active auroras.

Up until the launch of the POLAR spacecraft, most platforms capable of observing omega bands were limited in what they could say about their development in a global context. Global auroral imagers either lacked spatial-resolution, time-resolution or sensitivity to observe the detailed formation of omega bands over large space and time scales (e.g., DMSP acquired only a single scanned image per orbit, Dynamics Explorer took 12 min to acquire an image, Viking was a snapshot style imager with a non-ideal orbit and launched during solar minimum.) And ground-based all-sky imagers had field of views that were too small for this purpose. The sensitivity and resolution of the POLAR auroral imagers (UVI and VIS) combined with the high apogee of the POLAR orbit (and operations throughout a solar maximum) offered the first opportunity to explore how omega bands form and evolve in relation to other types of activity especially over long time periods.

Using the POLAR VIS high-resolution imagery, Henderson et al. (2002) and Henderson $(2009,2012,2016)$ have shown that auroral streamers ejected from the active poleward auroral arcs can evolve directly into auroral torch structures and contribute to the formation of auroral omega bands. Figure 12 (adapted from Henderson et al. (2002)) shows an example of this evolution, with a Poleward Boundary Intensification leading to an auroral streamer and ultimately a torch structure on the equatorward arc. Henderson et al. (2002) 


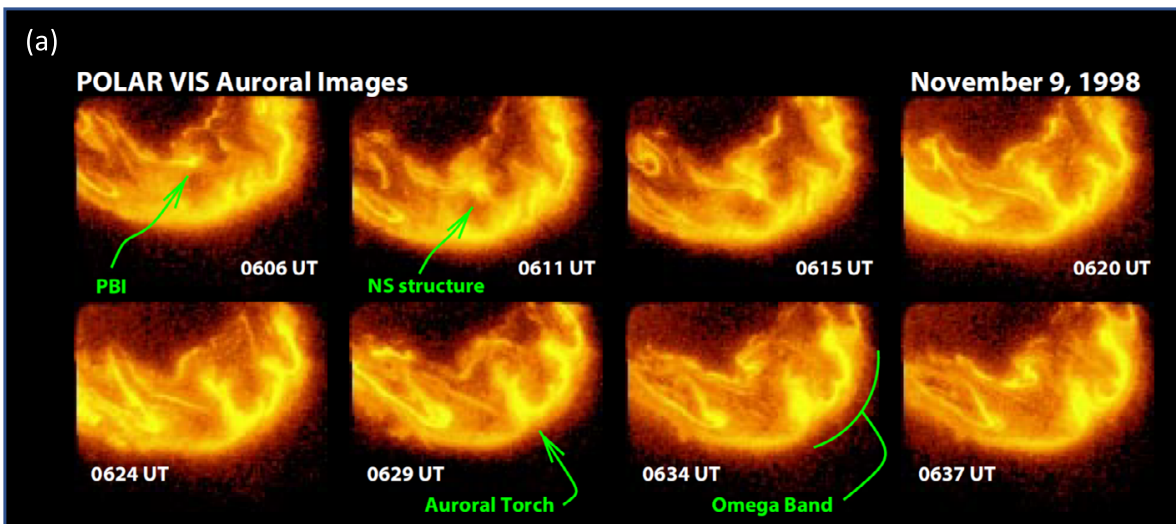

(b)
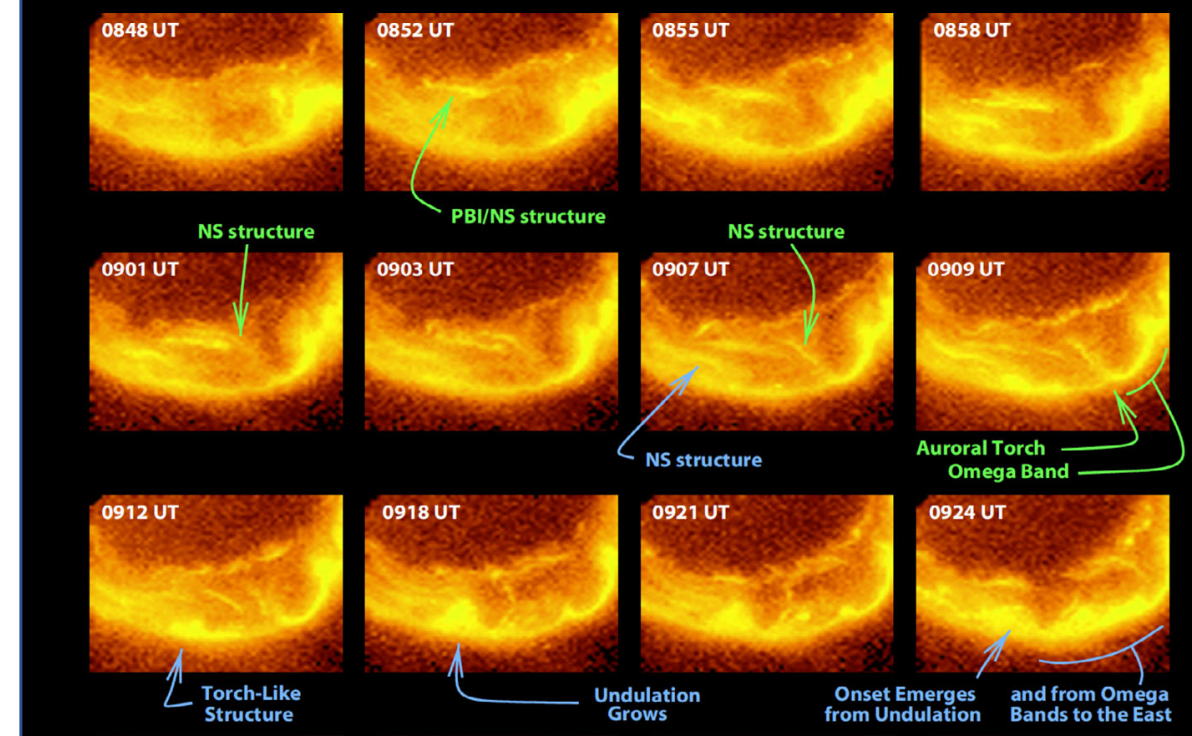

Omega Band
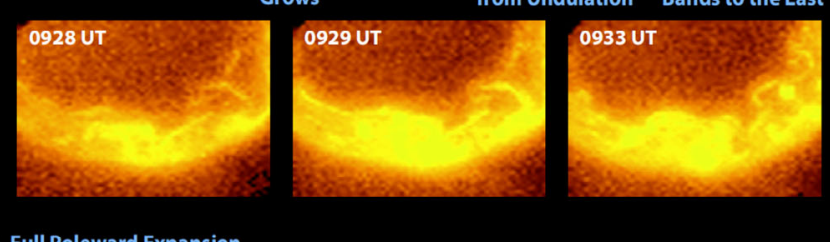

Full Poleward Expansion

Fig. 12 Examples showing evolution of auroral streamers into torches and omega bands. (Adapted from Henderson et al. 2002)

put forth three scenarios by which the fast magnetospheric flows associated with streamers (see above) might result in the formation of omega bands: (1) a series of fast flows from the same region arriving at different times drift eastward creating a series of omega bands forming from the same location; (2) a group of fast flows from different locations arrive 
near-simultaneously at the auroral boundary and drift eastward creating a series of omega bands forming at different locations; (3) a single fast flow excites the growth of an azimuthal wave at the inner edge of the plasma sheet. Since BBFs already have an upward/downward FAC pair, this framework resolves issues with the FAC structuring and ground signatures and removes the need for the generated omega bands to be a periodic wave. In addition, multiple streamers can occur simultaneously and at different longitudes which explains how pre-existing omega-band structures can be interrupted by new torch-like forms (e.g. Fig. 13).

As the forms drift eastward, further evolution, growth and distortions of the torch-like disturbances occur. The arrival of the fast flow, which is typically a plasma-depleted flux tube (e.g. Chen and Wolf 1993; Sergeev et al. 1996) may be sufficient to create the inward energy density necessary for the generation of KH/RTI waves (Yamamoto 2009) and so these mechanisms may work together. However, magnetospheric observations of such a shear flow are yet to be reported. Observations from the magnetotail during the occurrence of omega bands have shown the occurrence of fast flows at the same time but different locations of omega bands, although fast flows are fairly ubiquitous during substorm activity (Weygand et al. 2015). Similarly, broadband, $<1 \mathrm{keV}$ electron populations have been observed close to the mapped location of omega bands, but the variation in electron fluxes did not align with the passage of the bands (Wild et al. 2011).

Figure $14 \mathrm{~b}$ also shows the development of a torch-like structure on the western edge of the omega-band region, but this is seen to grow in intensity and expand poleward ultimately leading to the development of a new "embedded" auroral substorm onset. This type of activity had been noted much earlier by Oguti (1973) (but not in the context of streamers, torches and omega bands) who referred to such events as "contact breakups". It is likely that at least some of the streamer-induced breakups observed by Nishimura et al. (2010b) with the THEMIS ASI imagers are contact breakups of this sort.

\subsection{Implications and Outstanding Issues}

The proposed BBF generation mechanism for torches, omega bands and streamer-induced contact breakups provides a unifying framework for the complex auroral dynamics observed during sustained driving conditions that typically accompany driven substorm recovery phases and active double oval configurations (representative of SMC-like intervals). The mechanism resolves a number of previously puzzling features of omega bands including: why the bands are often so irregular, the nature of the paired up/down FAC structures and Ps6 pulsations, the fact that torches are activity centers for pulsating aurora, the energetic precipitation signatures. It also provides a potential mechanism by which the plasma in the inner magnetosphere may become unstable to KH-based instabilities that facilitate further excitation of distortions at the poleward edge of the diffuse aurora. However, several issues remain. Firstly, not all omega bands are observed to form following the arrival of streamers or magnetotail flows and the proportions of flow-driven bands is unclear. This also raises the questions as to what causes the non-flow driven bands. Furthermore, omega bands predominantly occur during periods of enhanced Kp while magnetotail fast flows are fairly ubiquitous during substorm so what plasma conditions prevent or allow the occurrence of omega bands. Also noted is that torches evolve over their lifetime, but it is unclear what controls this evolution and how this is linked to the evolution of magnetotail fast flows or depleted flux tubes in the magnetosphere.

The excitation of torches and omega bands in the westernmost auroral bulge seems to coincide with that region becoming more unstable to further distortions. This region (typically pre-midnight) is where auroral onsets (spontaneous or contact breakup types) tend to occur. 


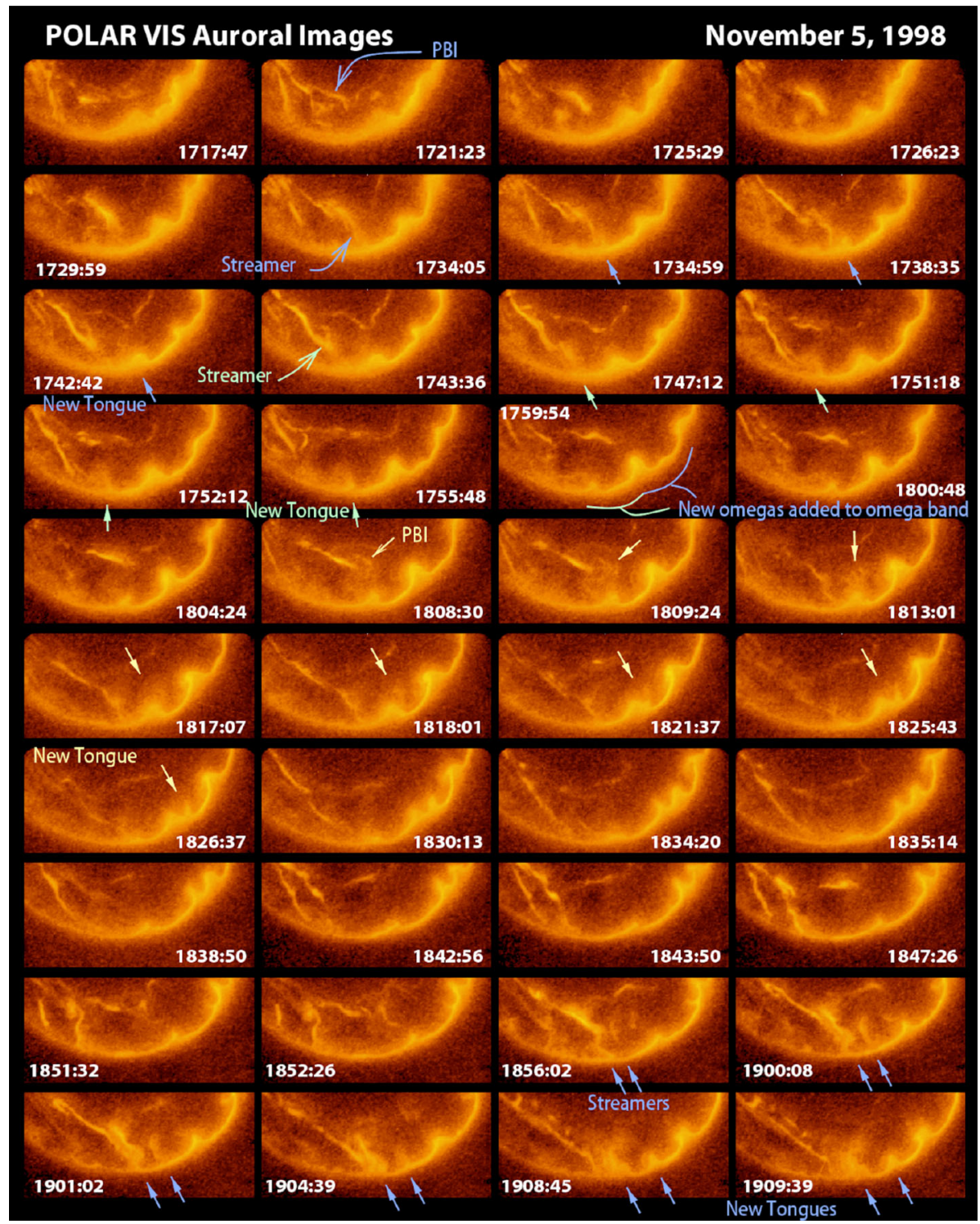

Fig. 13 Evolution of the northern auroral distribution over $\sim 2 \mathrm{~h}$ time interval on Nov 5, 1998 acquired with the POLAR/VIS LR camera. This sequence clearly shows how streamers can evolve into torches and how pre-existing omega forms can be interrupted by new torches (see yellow annotation as an example). Note that additional evolution/growth occurred following the creation of each torch. Also note that not all instances of streamer $\rightarrow$ torch formation has been annotated here

Thus, the occurrence of torches and omega bands may be indicative of changing plasma conditions in the magnetotail that increases the likelihood of different modes of variability. Understanding and isolating the different physical processes that arise throughout the magnetotail and how this arises from changing plasma conditions remains a key open question in magnetospheric physics and hence in the understanding of meso-scale auroral forms. 
(a)
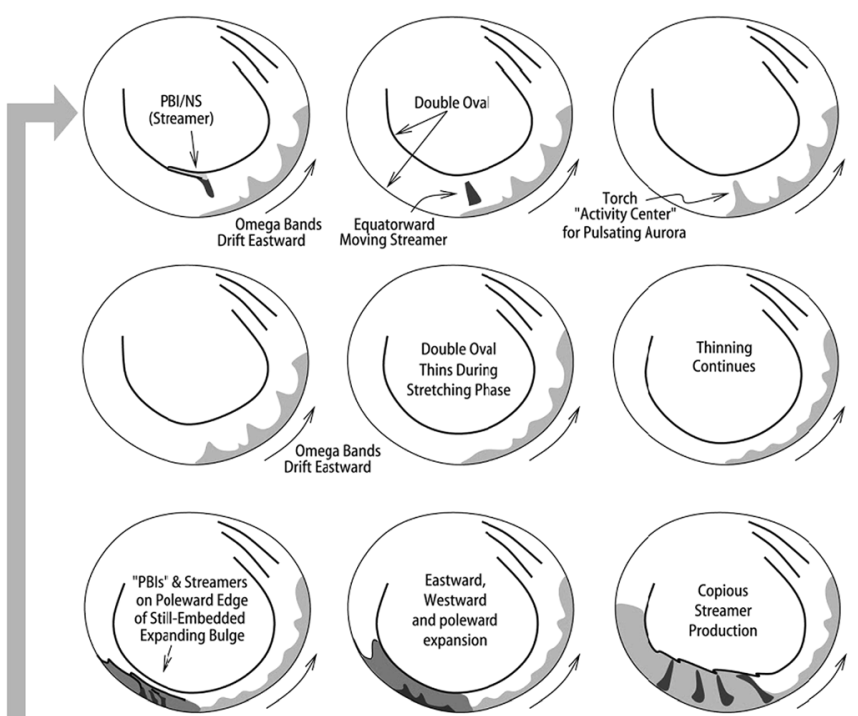

"Activity Center" for Pulsating Aurora

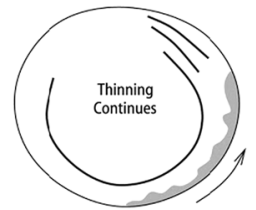

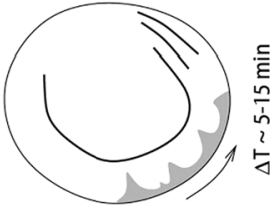
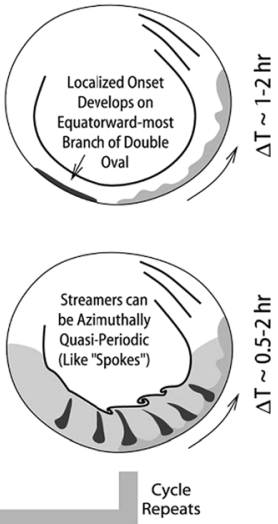

(b)

\section{Activation of Poleward Boundary}
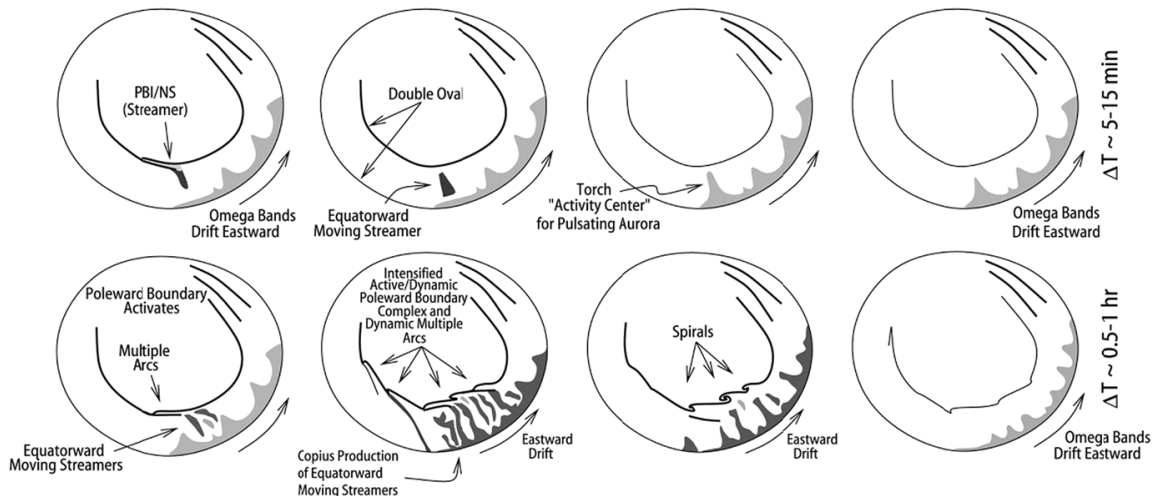

Fig. 14 A schematic showing the development of torches and omega bands. Top panel shows how this activity is related to the substorm cycle and the bottom panel shows an SMC-like interval of activity without the occurrence of new substorm onsets. From Henderson (2012)

\section{Auroral Beads}

\subsection{Definitions}

The term 'auroral beads' has become the commonly used term to describe spatially periodic auroral forms typically detected at or just before the substorm auroral onset. Originally described as 'azimuthally spaced auroral forms' (Henderson 1994; Elphinstone et al. 1995; 

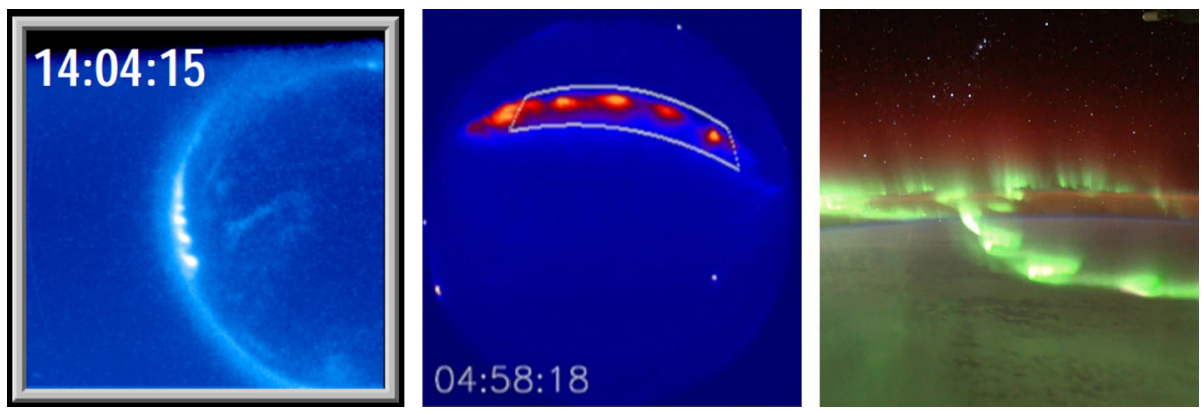

Fig. 15 Examples of auroral beads observed by the IMAGE FUV instrument (Henderson 2009), the THEMIS ASI at Gillam (Kalmoni et al. 2015), and from the International Space Station (from https://www.cosmos.esa.int/web/arrrgh/)

Voronkov et al. 1999, 2000) from data from the Viking global auroral imagers, the initial brightening along a preexisting or a newly formed arc at substorm onset is almost always observed in the form of a wavy auroral pattern (Kalmoni et al. 2017). The availability of data from networks of ground-based optical instruments has provided unprecedented observations of the these structures, which are now commonly referred to as auroral beads (Donovan et al. 2006; Liang et al. 2008; Rae et al. 2009; Sakaguchi et al. 2009). Unlike omega bands (see Sect. 4), auroral beads appear as are localised bright patches of aurora associated with an accelerated electron population (Motoba and Hirihara, 2016), as opposed to enhancements of diffuse aurora, that may or may not eventually take on the form of a series of auroral curls. Figure 15 shows a series of examples of auroral beads taken by the IMAGE FUV instrument, a THEMIS ASI and by astronauts on the International Space Station.

Early observations of auroral beads showed regularly spaced auroral bright points separated along a quiet arc by 130-585 km (Elphinstone et al. 1995). More recent statistical studies using ground-based data have shown wavelengths down to of 50-100 km (Liang et al. 2008; Nishimura et al. 2016) when tracking the brightest features in auroral keograms. However, quantitative analysis of the auroral power at all observable wavelengths has shown the presence of waves down to $1.6 \mathrm{~km}$ scales (Sakaguchi et al. 2009; Kataoka et al. 2011; Kalmoni et al. 2015), but that waves at the $100 \mathrm{~km}$ scale tend to have much larger power, thus are the most prominent. From both space and ground-based observations, the scales observed have been limited by the resolution of the instruments. These smallest observed wavelengths are smaller than the electron inertial lengths above the auroral region and that the larger wavelengths map to $\sim 1000-3000 \mathrm{~km}$ widths in the magnetotail.

One of the key features of auroral beads is the near simultaneous exponential growth in their brightness across a range of scales. The exponential growth rate of the total auroral brightness (Nishimura et al. 2016) and of the individual wavenumbers (Kalmoni et al. 2015) of the auroral beads is typically $\sim 0.04 \mathrm{~s}^{-1}$, although different wavelengths grow at different rates and for different lengths of times. Growth rates above $0.1 \mathrm{~s}^{-1}$ have been derived from ASI data (Rae et al. 2010) and of $0.005 \mathrm{~s}^{-1}$ (Henderson 2009) have been reported from global auroral imagers. The differences in the growth rates from ground and space-based observations may result from differences in resolution; just as global imagers cannot resolve small scale $(\sim 10 \mathrm{~km})$ waves, individual ground-based ASIs cannot examine larger scale $(>500 \mathrm{~km})$ waves, thus there are significant difficulties in examining the whole parameter space. 


\subsection{Drivers/Causes}

The exponential growth of auroral beads, with similar rates to the growth in wave power observed by co-located ground magnetometers (Sakaguchi et al. 2009; Rae et al. 2012), and their spatially periodic form indicates that they arise from the linear phase of a plasma instability. Observations from conjugate auroral observatories has shown nearly coincident growth of auroral beads in both the northern and southern hemispheres, pointing to a common, magnetospheric source (Motoba et al. 2012) at a distance of $\sim 10 \mathrm{R}_{\mathrm{E}}$ downtail. However, which instability remains an open question.

A number of instabilities have been implicated in the generation of auroral beads including shear flow ballooning (Viñas and Madden 1986; Voronkov et al. 1997), kinetic ballooning (Cheng and Lui 1998), kinetic ballooning interchange (Pritchett and Coroniti 2010) and cross-field current (Lui et al. 1991). Each have been suggested due to producing growth rates or wavenumbers similar to those observed for auroral beads for reasonable, but unobserved, conditions in the source region (Friedrich et al. 2001; Cheng and Zaharia 2004; Liang et al. 2008; Sakaguchi et al. 2009; Rae et al. 2010). However, there is sufficient variation in the plasma conditions close to the mapped source of the beads that the theoretical growth rates and wavenumbers can be made to match the observations. By examining the observed profile of the normalised growth rates against wavenumber, which showed a distinct peak for wavelengths of $\sim 100 \mathrm{~km}$, with the profiles predicted for the shear-flow ballooning and cross-field current instabilities, Kalmoni et al. (2015) found that while both provided comparable growth rates, only the shear-flow ballooning instability reproduced the observed growth rate vs wavenumber profile. From the same underlying data, Lui (2016) showed that the profile of the average, rather than normalised, growth rates could be reproduced by the cross-field current instability. A further statistical study examining the propagation speed vs wavelength of the dominant auroral beads and their growth rates vs duration also concluded that the cross-field current instability was unlikely to be the source of auroral beads, but that the kinetic ballooning interchange instability provided a good fit to the data (Nishimura et al. 2016). Results from these studies are summarised in Fig. 16.

Auroral observations provide information on the growth of the instability associated with auroral beads, but limited information about the plasma conditions and movement. Following on from observations of fast flows near auroral beads by Hosokawa et al. (2013), Gallardo-Lacourt et al. (2014a) used SuperDARN radars working in high-resolution mode to infer a clockwise flow shear around auroral beads, which indicated the presence of an upward field-aligned current in the center of the shear giving rise to the individual beading structures. These flows were qualititatively similar to those reported from simulations by Pritchett and Coroniti (2010, 2013), also associated with the kinetic ballooning interchange instability.

Understanding the mechanism by which particles are accelerated along the magnetic field to generate bright auroral beads provides constraints on the physical mechanisms at play. As has been examined at length (e.g. Paschmann et al. 2003), both broadband and monoenergetic electron populations can result in bright aurora, and the mechanisms by which the quiet arc from which auroral beads arise remain a mystery. As noted above, observations of the ionospheric plasma motions associate with auroral beads indicates that the auroral bright spots are associated with upward field-aligned currents. Given the known limitations of the magnetosphere-ionosphere system to support field-aligned currents (Knight 1973), the driving process or processes in the magnetotail must either accelerate electrons or provide the conditions for electron acceleration at some point along the magnetic field.

By comparing in-situ observations of the electron pitch-angle distribution taken by Reimei above auroral beads with optical emission at the spacecraft footpoint, Motoba and 

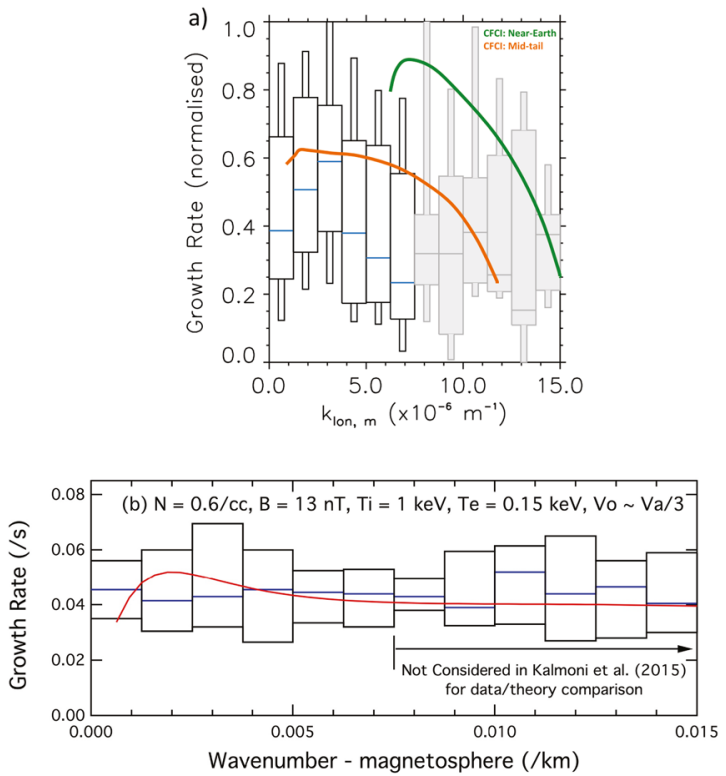
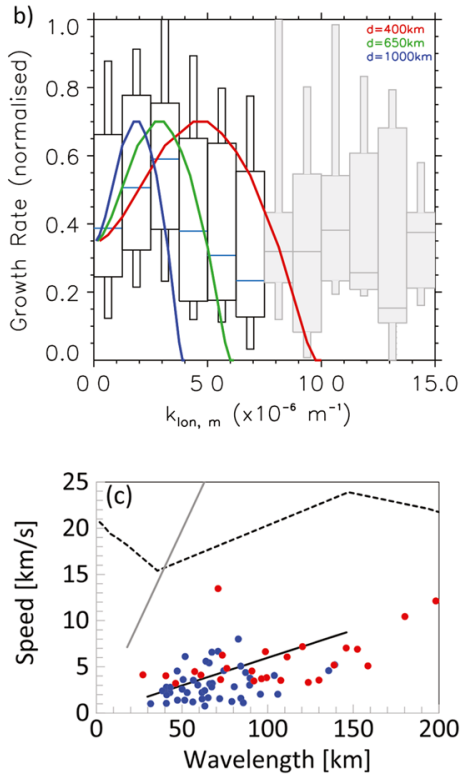

Fig. 16 Comparisons of auroral bead properties with those predicted for various instabilities. (Top) Normalised growth rates versus mapped longitudinal wave number overlaid by the expected results for (left) the cross-field current instability and (right) the shear-flow ballooning instability. Greyed out bars indicate those observations that are no statistically significant (from Kalmoni et al. 2015). (Bottom left) Growth rate versus mapped longitudinal wave number (from the same data) overlaid by an alternative calculation from the cross-field current instability (from Lui 2016). (Bottom right) Wavelength versus phases speed overlaid by the expected results for the current driver ion cyclotron instability (Perraut et al. 2000, grey line), the kinetic ballooning instability (Pritchett and Coroniti 2010, black line) and the cross-field current instability (Lui et al. 1991, dashed line) (from Nishimura et al. 2016)

Hirahara (2016) inferred that the optical emission was associated with a 3-7 keV monoenergetically accelerated electron population (see Fig. 17) associated with a quasi-static potential drop rather than from an Alfvén wave accelerated population. However, their observations do not show a clear horseshoe distribution as is typically associated with monoenergetic electron acceleration, but rather higher energies at pitch angles close to 90. Qualitatively similar distributions arise from simulations of inertial Alfvén waves (Watt et al. 2006). From detailed 2D analysis of the all-sky images of beads, Kalmoni et al. (2018) determined an observational dispersion relation from a set of auroral beads which had a remarkable match to that of waves on the kinetic branch of shear Alfvén waves with short perpendicular scales, as modeled by Watt et al. (2006), strongly suggesting a wave driven electron acceleration mechanism.

\subsection{Outstanding Issues}

While much progress has been made in understanding auroral beads, there is still no consensus as to which instability or instabilities are the drivers of these meso-scale auroral forms, although the various ballooning instabilities seem to be favoured. Largely, this has arisen due to qualitative rather than quantitative comparisons between observations and theory or simulations or comparisons based on different assumptions of the conditions in the source region. Given that the various instability theories give non-unique wave scale sizes, growth 

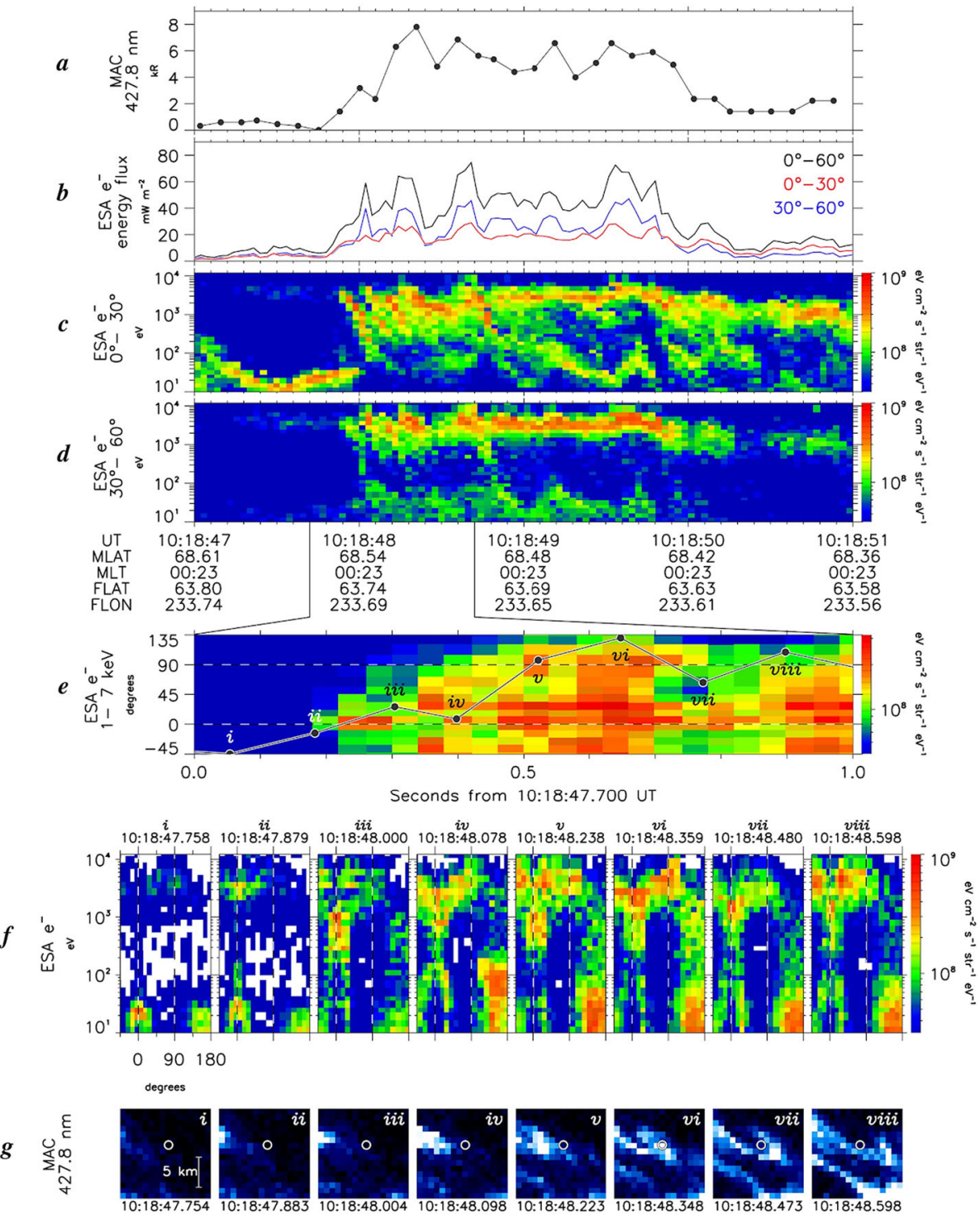

Fig. 17 Detailed comparisons between auroral and electron flux measurements on the same field line. (a) Temporal variation of the MAC $427.8 \mathrm{~nm}$ intensity at the Reimei footprint (see Sect. 2.2) for 10:18:47-10:18:51 UT. (b) Electron energy fluxes at pitch angles of 0-30 (red), 30-60 (blue), and 0-60 (black), respectively. (c) Electron energy spectrogram at 0-30 $0^{\circ}$. (d) Electron energy spectrogram at $30-60^{\circ}$. (e) Electron pitch angle spectrogram averaged over energies of 1-7 keV for $1 \mathrm{~s}$ from 10:18:47.700 UT, together with the MAC $427.8 \mathrm{~nm}$ intensity variation. (f) Electron energy-pitch angle distribution at the nearest time to each of i to viii. (g) Zoomed-in MAC $427.8 \mathrm{~nm}$ images. Reproduced from Motoba and Hirahara (2016)

rates and propagation speeds for reasonable plasma conditions in the source region, it is unlikely that ground-based observations will be able to unequivocally identify the source mechanism. However, coordinated auroral and in-situ observations of the instability region 
will be challenging, given its predicted small size and the necessity to measure, for example, plasma gradients in three dimensions on short time-scales.

Auroral beads are uniquely discussed in terms of their association with substorm onset. Evidence suggests that most, if not all substorms, are preceded by auroral beads (Nishimura et al. 2016; Kalmoni et al. 2017). However, substorms are relatively easily identified in auroral data and can easily be searched for using automated routines (e.g. Forsyth et al. 2015). Conversely, auroral beads are relatively difficult to identify in such an automated manner and, as such, whether or not they appear at other times has largely been overlooked. Their appearance (or lack of appearance) at times not leading into substorm activity, and the plasma conditions at those times may provide useful insights into the conditions and physical processes that lead to large-scale dynamic changes in the magnetosphere.

\section{Giant Undulations}

\subsection{Definition}

Although the equatorward edge of the diffuse aurora is typically quite smooth, at times large-scale undulations can develop. These were first discovered by Lui et al. (1982) using Defense Meteorological Satellite Program (DMSP) imagery. They predominantly occur in the afternoon to evening sector and have amplitudes of 40-400 km and wavelengths of $\sim 200-900 \mathrm{~km}$. When the amplitude of the undulation is comparable to the wavelength, they are classified as "Giant Undulations" (GUs). Some examples of GUs acquired with the DMSP/OLS imager are shown in Fig. 18 (from Henderson et al. 2010). Observations of GUs the TIMED/GUVI spacecraft-borne imager mostly occurred during geomagnetic storm times (Zhang et al. 2005), but observations from ground imagers across a solar cycle showed that more than half of the observed GU events occurred outside of storm times (Baishev et al. 2012).

GUs are quite different from omega bands. As discussed above, omega bands are a premidnight to morning sector phenomenon but, more importantly, the tongues of luminosity in omega bands point poleward, i.e. they are extensions into the auroral oval, while for GUs the tongues of luminosity point equatorward. In addition, omega bands are often quite irregular and occur near the poleward edge of the diffuse aurora while GUs are much more wave-like and appear on the equatorward edge of the diffuse aurora. To further illustrate the differences, Fig. 19 shows a composite image of DMSP/OLS and POLAR/VIS Earth camera data from a storm that occurred on Nov 9, 1998 (both images were taken at similar times.) The DMSP image shows a series of very well-defined GUs on the equatorward edge of the dusk-side diffuse aurora. Farther to the east, prominent auroral streamers can be seen which occurred copiously throughout this storm in association with torch and omega band formation (note that this is the same storm event that is shown in Fig. 12 above.)

Although DMSP photographs were incapable of detecting motion associated with the GUs, using successive orbital passes of the DMSP spacecraft Lui et al. (1982) were able to determine that GUs can persist for time periods of 0.5-3 hours, although subsequent statistical studies have shown typically shorter durations (Baishev et al. 2012). While early studies of undulations by Provadakes et al. (1989), Mendillo et al. (1989), Murphree and Johnson (1996) were not able to detect azimuthal motion of the forms, subsequent studies have consistently shown that the undulations propagate sunward on the duskside. Nishitani et al. (1994) reported a duskward phase speed of 540-650 m/s combined with a strong latitudinal velocity shear during a 22 min period of observation and Baishev et al. (2000) reported a 
Fig. 18 An example of giant undulations of the equatorward edge of the diffuse aurora as seen in DMSP/OLS imagery. The value of the $\mathrm{Kp}$ index at the time of the undulations is shown. The arrows indicate the direction of the equator. Typically, giant undulations occur during high $\mathrm{Kp}$ intervals that are associated with high convection intervals. Adapted from Henderson et al. (2010)

Fig. 19 A composite of a DMSP OLS image on top of a POLAR/VIS Earth Camera image showing where giant undulations tend to occur in relation to the large-scale auroral distribution. Omega bands are also typically seen to form in the region where the auroral streamers form. From Henderson et al. (2010)
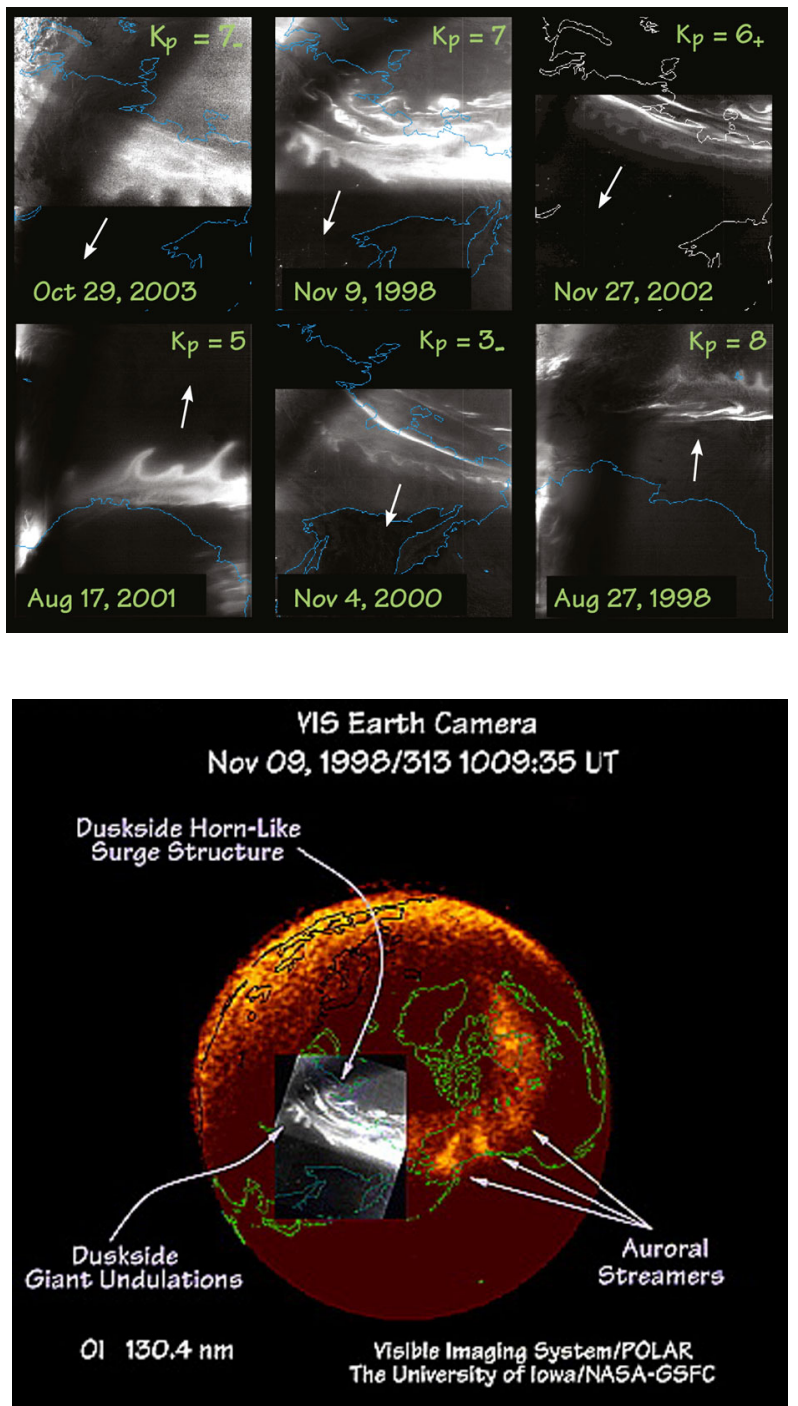

duskward phase speed of $\sim 700 \mathrm{~m} / \mathrm{s}$ for undulations that developed following a substorm and persisted for more than an hour. Henderson et al. (2010) also reported a sunward phase speed of $\sim 600 \mathrm{~m} / \mathrm{s}$ also in association with strong SAPS observed by multiple DMSP crossings. Pc5 magnetic pulsations are also observed on the ground in association with the passage of giant undulations (Baishev et al. 2000; Henderson et al. 2010).

\subsection{Drivers/Causes}

Originally, Lui et al. (1982) suggested that undulations in the equatorward edge of the diffuse aurora may be due the Kelvin-Helmholtz Instability at the plasmapause. On the dusk-side, a velocity shear is expected between the corotating plasmasphere (tailward on the dusk-side) and the sunward plasma sheet flow. However, this hypothesis was called into question by 

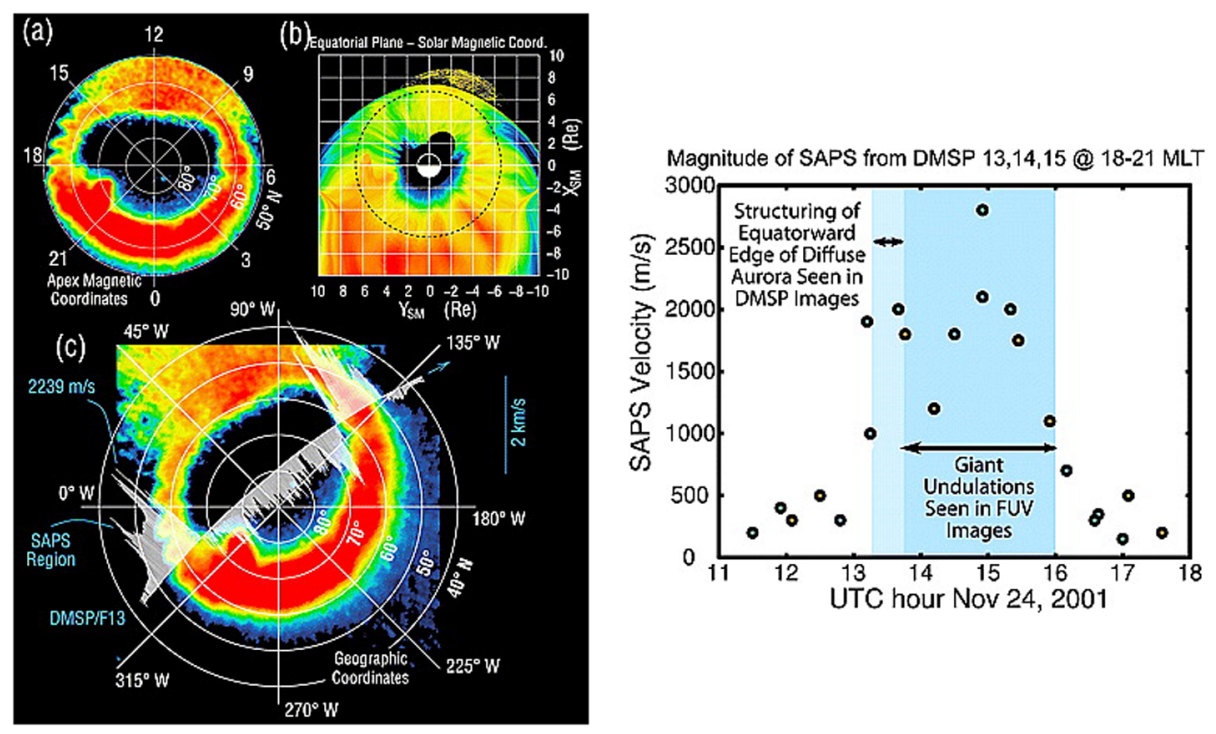

Fig. 20 Left panel: (a) Giants undulations seen in the IMAGE/FUV imagery (equatorward edge between 15-19 MLT). (b) Mapping to equatorial plane. (c) DMSP/F13 overflight shows GU region is associated with enhanced SAPS. Right panel: GUs occur when SAPS are high. From Henderson et al. (2010)

Kelley (1986) who showed, that the nominal shear at the plasmapause is much too small for such an instability to develop, based on the "shear flow ballooning instability" analysis of Viñas and Madden (1986). Instead, Kelley (1986) proposed that a much larger shear flow on the duskside associated with "subauroral ion drift" events (SAIDs) or "polarization jets" (PJs) was responsible. In more recent literature, these are referred to as SAPS (Foster and Burke 2002). Yamamoto et al. $(1993,1994)$ used to $2 \mathrm{D}$ particle simulation to suggest that a polarized arc sheet, arising from a quasi-statically driven auroral arc just equatorward of the diffuse proton aurora, would be unstable to the Kelvin-Helmholtz instability and could account for the observations of GUs. Using global auroral imaging results from POLAR and IMAGE, Henderson et al. (2010) studied the development of a GU event from start to finish and were able to confirm that the development of GUs is associated with strong SAPS (see Figs. 19 and 20).

Henderson et al. (2018) also showed an unusual breakup-like event that appears to have grown explosively in the dusk-to-midnight sector near a region of growing undulations (though not giant undulations). Following the onset, the equatorward edge of the diffuse aurora in this sector was violently disrupted in an unusual manner. They "speculate that the event may be due to an explosive disruption of the plasmapause - possibly due to an instability like the shear flow-ballooning instability driven by large shear flows between the plasmasheet and plasmasphere resulting from enhanced SAPS flows. These types of events might only occur during storms and may be responsible for structuring the plasmapause, feeding long-lived drainage plumes and possibly feeding into Steve-like subsuroral emissions."

Recent observations combining THEMIS ASI data and in-situ observations from the Van Allen probes suggest that auroral undulations are a manifestation of ULF waves in the plasmasphere (Motoba et al. 2015). To date, these observations appear to be the only reported observations of the in-situ plasma close to the source of auroral undulations. The ground 
observations were used to infer that the ULF waves associated with the undulations had an azimuthal wave number of $m \sim-103$, while the in-situ observations of the electric and magnetic fields revealed that the waves were a second harmonic poloidal wave existing just outside the plasmasphere. Motoba et al. (2015) reported, but did not show, an ionospheric flow of $300-450 \mathrm{~m} / \mathrm{s}$ just equatorward of the undulations, hinting at a possible SAPS channel. The propagation of the undulations was $3-4 \mathrm{~km} / \mathrm{s}$, significantly faster than the reported ionospheric flows, but this may be as a result of the SuperDARN flows being determined by E-region echoes (as discussed above). However, although the ULF waves may provide the mechanism by which electrons with energies of $10 \mathrm{~s}$ of $\mathrm{keV}$ are scattered into the ionosphere, particularly if they have a compressional component (Rae et al. 2018), the source of these waves and their relationship to SAPS was not resolved by this study.

\subsection{Implications and Outstanding Questions}

Giant undulations have, thus far, received relatively little attention in the literature. This may, in part, be to their relatively sparse occurrence (54 events in solar cycle 23 - Baishev et al. 2012) or due to the lack of corroborating in-situ observations in the magnetospheric source region. However, they are a clear, long-lived indicator of large-scale processes occurring in the inner magnetosphere, far from the plasmasheet dynamics that drive many other meso-scale auroral forms. As with other spatially period auroral forms, plasma instabilities in the source region are key to the growth of GUs. Both the shear-flow ballooning instability and Kelvin-Helmholtz instabilities remain potential candidates, but observations of a shear flow at near-ionospheric altitudes are insufficient to rule out either. Further robust modelling of this region, with a view to isolating the dominant instability, is required to provide indications of the required conditions to be measured by spacecraft and whether these plasma conditions can be measured by existing instrumentation. Such modelling must not only generate the undulation itself but, unlike auroral beads for which the instability can grow until the system breaks down, enable the large-scale waves to exist for long periods of time.

In-situ observations of the inner magnetosphere, in particular the conditions at and around the plasmapause, may provide further insights into the formation of GUs. The nonlinear growth of instability responsible for GUs may lead to a layer of intermixed plasma near the plasmapause, which in turn may help to explain some observation of some puzzling subauroral structuring. Sustained activity of this sort may also feed long-lived drainage plumes observed by Borovsky et al. (2014). Finally, a firm grasp on the driving mechanism combined with observations of undulations may provide a new capability to remotely sense strong SAPS flows.

\section{Magnetic Mapping}

Whereas the short-time and small-scale auroral processes can significantly be controlled and/or modified by the ionospheric processes, it is common opinion that the magnetosphere is mainly responsible for generating and shaping the mesoscale auroral structures and largescale auroral distributions. However, as discussed above, directly linking auroral features to plasma structures and dynamics in the magnetosphere is non-trivial, especially during active and dynamic intervals.

Directly mapping the magnetospheric source to bright aurorae by examining the particle distribution functions is challenging because the loss-cone size in the high-beta (source) region is so small as to be unresolved with current instrumentation. Similarly, the effect of 
magnetic focusing means that ion beams generated by auroral acceleration processes in the strong-B region above the ionosphere become increasingly narrow and similarly unresolvable by the time they reach the weakest magnetic field strength regions in the magnetotail. Thus, in order to learn about the magnetospheric roots of particular auroral forms we have to map these forms into the equatorial magnetosphere along the magnetic field lines using some magnetospheric model.

It is commonly accepted that most of auroral oval is mapped to the magnetotail plasma sheet, a large hot plasma reservoir captured on closed magnetic field lines. Most of its volume is occupied by the region of weak magnetic field in the plasma sheet center (say, where $\mathrm{Bz}$ is below 20-30 nT, a value comparable to the lobe magnetic field) where the plasma- $\beta$ parameter is large. As magnetic field here is significantly modified by local electric currents generated by the hot plasma itself, and plasma motions are not fully dictated by the applied boundary conditions, this region plays an active role in the tail dynamics. This particularly manifests on the global scale as the energy storage/explosive dissipation phases in the magnetotail constituting the substorms, as well as a rich inhomogeneous structure of the active plasma sheet on medium-to-small scales, which exists at any activity level but highly enhanced during substorms.

One of most available mapping tools is still the mapping along the magnetic field lines using the magnetospheric magnetic field models. Currently three kinds of such models are available: statistical empirical models, adaptive models and global MHD models, each with advantages and drawbacks. In general, statistical models are relatively quick to run, but provide the average conditions and thus struggle with more dynamic times; adaptive models build on statistical models by providing further boundary conditions to be met, but are limited by the number of observations available; global MHD models can be slower to and more complex to run and, in the past, have not been accurate enough to represent magnetospheric magnetic field and its variations.

The most well-known and widely used models are statistical empirical magnetospheric models, constructed based on a huge historical archive of spacecraft observations. These models typically attempt to deconstruct the observed magnetic field into a series of defined current systems, the strength of which is then related to solar wind drivers and geomagnetic activity measures (see review by Tsyganenko 2013), although more recent models use empirical basis functions with no imposed current system configuration (e.g. Andreeva and Tsyganenko 2016; Tsyganenko and Andreeva 2016). Two major problems of these models for mapping purposes are known. Firstly, since these models describe average configurations, they fail to reproduce large dynamical changes or localised changes. For example, both the highly-stretched magnetotail and locally (and globally) dipolarised magnetotail, which develop during substorm growth and expansion phases significantly deviate from the average model. Statistically the average mapping errors from the nightside magnetosphere near GEO orbit to the ionosphere are estimated to be about $1-2^{\circ}$ (Shevchenko et al. 2010). Another problem is that, because of their fitting method (minimizing the RMS deviation of modelled and observed B over the entire magnetosphere), these models do not particularly care about $\mathrm{Bz}$ values in the regions where $\mathrm{Bz}$ is small. Therefore, the details of $\mathrm{Bz}$ distribution and mapping are especially questionable in these models in the midtail region.

Adaptive modelling, which is a kind of data assimilation, combines in-situ magnetic field measurements with statistical models to optimize their input parameters. With good spatial coverage, this makes possible to reconstruct the concurrent configuration and follow its time-dependent behaviour in that region (Sitnov et al. 2008; Kubyshkina et al. 2011; Stephens et al. 2019) and generally improves the results compared to unoptimized versions of the models (Brito and Morley 2017). Quite expectedly, using more satellites in the optimization procedure yields more accurate results, thus the effectiveness of adaptive models 


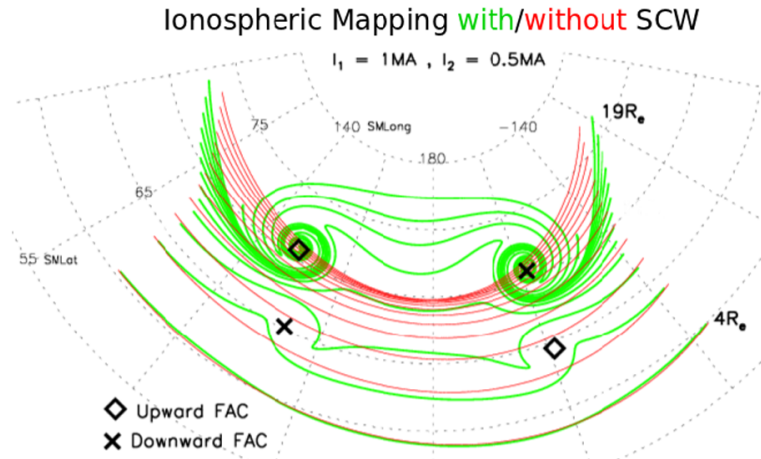

Fig. 21 Ionospheric mapping of equidistant equatorial contours (distances change by $1 \mathrm{R}_{\mathrm{E}}$ step between 4 $\mathrm{R}_{\mathrm{E}}$ and $19 \mathrm{R}_{\mathrm{E}}$, equatorial distances are labeled for selected circles). The red lines show neutral sheet mapping using the T89+IGRF model; the green lines show mapping of the same points using the SCW2+T89+IGRF model. Ionospheric locations of upward (downward) FACs are indicated by diamond (cross) symbols correspondingly (after Nikolaev et al. 2015)

is tied to the available observations. However, these models still rely on the underlying current systems prescribed within the model. While some prescriptions of these are fairly rigid (e.g. Kubyshkina et al. 2011), others expand the magnetic perturbations in terms of basis functions (e.g. Stephens et al. 2019). In either case, these models can only account for current systems that are included and may struggle to resolve small-scale current systems adequately.

Previously the global MHD models, which solve the physics equations under realistic time-varying solar wind conditions, were not accurate enough to represent magnetospheric magnetic field and its variations. However, recent benchmarking of all kinds of models indicate that predictions of current GMHD models (incorporating the drift physics in the inner magnetosphere) may approach and even outperform the predictions of best statistical models during disturbed conditions (Kubyshkina et al. 2019), so their further development may provide us a useful tool for future research.

The effects of large-scale field-aligned currents may be under-represented in the statistical magnetospheric models. Structured FACs of different scale (absent from these models) are formed in the plasma sheet and linked to the aurora during active conditions (e.g. Murphy et al. 2013; Forsyth et al. 2014; Kepko et al. 2015). FACs strongly affect magnetic mapping by changing both the shapes of field-lines and the latitude/longitude/distance range of projections, but so far this aspect is poorly studied. Nikolaev et al. (2015) numerically investigated the problem by applying the recently-developed two-loop SCW model whose parameters (intensity and longitudes of SCW currents) can be evaluated from midlatitude magnetic variations. As illustrated by ionospheric mapping curves in Fig. 21, when the SCW is absent (red lines) the field line mapping of equidistant lines from the equatorial current sheet (tailward of $10 \mathrm{R}_{\mathrm{E}}$ ) provides the smooth lines in the ionosphere resembling the auroral oval. The addition of a 1 MA (Region 1 current) SCW causes two major effects illustrated by green lines: (a) ionospheric projections leap poleward in the dipolarized sector of the SCW resembling the poleward expansion of auroras by as much as $8^{\circ}$ latitude; (b) the overall deformation displays the pattern resembling an auroral bulge. The counter clockwise rotation pattern resembling the westward travelling surge is formed in the region around a major upward SCW current, it has a $\sim 1 \mathrm{hr}$ MLT azimuthal scale for the cited parameters. Similar deformations have been obtained in the MHD simulation of reconnection-related 
Rotation of structure due to mapping depending on mapping ratio $\mathrm{M}_{X} / \mathrm{M}_{Y}$
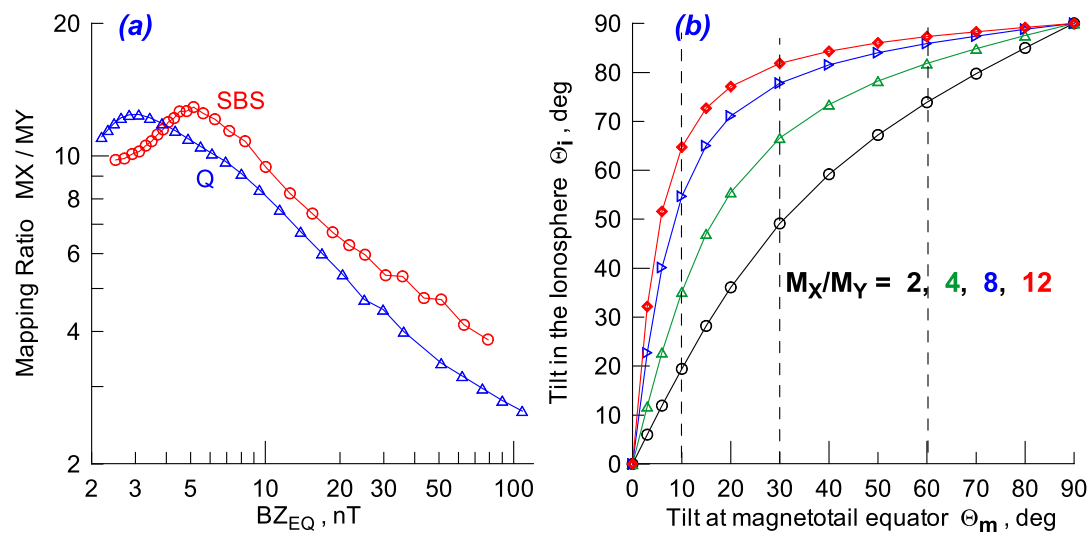

Fig. 22 Mapping ratio and rotation of the line segment during the mapping between equatorial magnetosphere and ionosphere (updated after Sergeev 2002). (a) Examples showing the $\mathrm{Mx} / \mathrm{My}$ dependence on the equatorial BZ values along the tail axis obtained for samples of quiet and substorm conditions using recent Tsyganenko and Andreeva (2015) model. (b) Relationship between tilts of magnetospheric line segment and its ionospheric projection depending on $\mathrm{Mx} / \mathrm{My}$

dipolarization (Birn and Hesse 2013) and have been shown to significantly modify spacecraft footpoints such that they track variations in the aurora (Chu et al. 2014). Irrespective of the auroral acceleration mechanism, these modeling results suggest that auroral bulgelike shaped auroras (with poleward expansion and, not necessarily moving, WTS) will be seen as long as the 3-d configuration of SCW currents is persistent in the magnetotail. The expected close relationship between SCW current and poleward expansion magnitude still waits a quantitative statistical confirmation.

Another deformation, unrelated to field-aligned currents, is that that mapping factors $M$ which describe the change of the magnetic flux tube size between the magnetosphere (index $\mathrm{m}$ ) and ionosphere (i) are different for different directions across the flux tube (e.g., Kauffman et al. 1990). Taking $\mathrm{Mx}=\mathrm{Xm} / \mathrm{Xi}$ and $\mathrm{My}=\mathrm{Ym} / \mathrm{Yi}$, where $\mathrm{X}$ and $\mathrm{Y}$ stands for the meridional and azimuthal directions across $\mathrm{B}$, correspondingly, the ratio $\mathrm{Mx} / \mathrm{My}$ is 2 for the dipole field, but significantly increases in the nightside current sheet region where $\mathrm{B}_{\mathrm{Z}}$ is small, as shown on examples in Fig. 22a. One consequence is that a circular flux tube section in the tail current sheet is transformed into E-W aligned form in the ionosphere. Another consequence is a rotation of the line segment towards E-W alignment, which can be very significant if mapping is performed from the region having a small $\mathrm{B}_{\mathrm{Z}}$ in the tail and thus a high Mx/My (Fig. 22b). For small Mx/My (close to a dipole field) the rotation is not large, but for large Mx/My (highly stretched fields) a nearly radial segment is rotated towards an azimuthal orientation in the ionosphere (say, by as much as $50^{\circ}$ in the ionosphere for a $10^{\circ}$ rotation in the magnetosphere if $\mathrm{Mx} / \mathrm{My} \sim 10$ ). This could account for the dominant zonal orientation of auroral forms. Previously it was used to explain a frequent E-W alignment of PBIs/auroral streamers connected to the plasma sheet fast flow channels (Sergeev 2002; Zesta et al. 2006, see Fig. 23). It may also be invoked to understand the preferential ovalaligned orientation of the auroral arcs A critical magnetospheric quantity which controls the amount of rotation during the mapping is the magnitude of equatorial BZ in the plasma sheet (Sergeev 2002). 

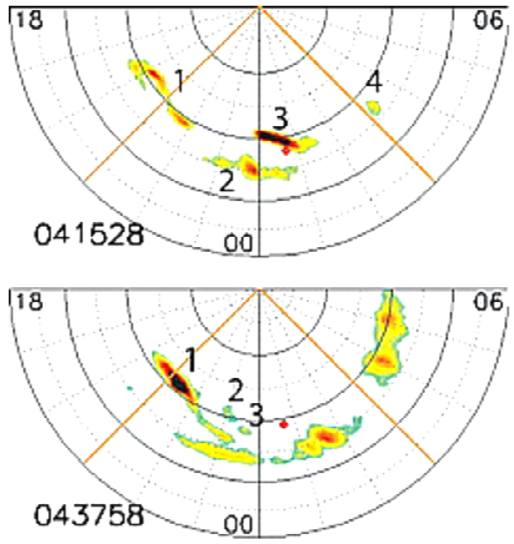
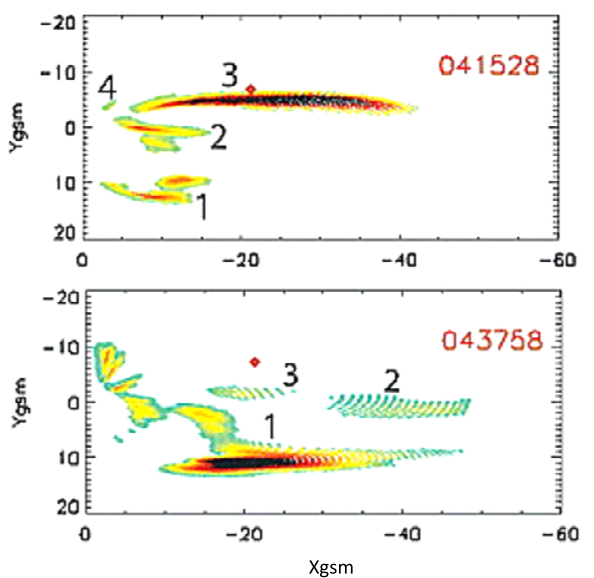

Fig. 23 IMAGE FUV data showing large-scale auroral structures, including PBIs, in magnetic coordinates and the projections of these auroral features along magnetic field lines to the center of the plasma sheet (right) (adapted from Zesta et al. 2006). The projected images show how apparently east-west aligned arcs may be produced from plasma structures aligned along the magnetotail

While magnetic modelling enables each point in the magnetotail to be traced to a unique point in each ionosphere, their limitations mean that they cannot be relied upon, particularly during active times. However, one can also apply different kinds of morphological mapping using tracers, which originate in specific places in the magnetotail but are observed in the ionosphere (see Paschmann et al. 2003). From them, the isotropy boundaries (IBs, the equatorward boundaries of extended isotropic loss-cone precipitation of energetic particles) are a most useful and well-known tool, providing useful low-altitude markers of equatorial $B_{Z}$ values (where $B_{Z}$ is roughly in the range 30 to $50 \mathrm{nT}$ for $30 \mathrm{keV}$ proton $\mathrm{IB}$, and roughly $\sim 5 \mathrm{nT}$ for $30 \mathrm{keV}$ electron IB). This method is useful in establishing the location of magnetic flux tubes containing specific auroras with respect to the high-beta plasma sheet region but requires in-situ observations of the low-altitude plasma in order to do so. Distinction from wave-induced precipitation mechanisms is often possible based on the energy dependence of isotropic loss-cone precipitation. A direct comparison between whistler-mode chorus activity in the magnetosphere and auroral brightness enabled Nishimura et al. (2010c) to exactly map the location of the THEMIS-A spacecraft when it was close to geosynchronous orbit, however such a mechanism requires that the source and resulting aurora can be readily identified. More recently, studies have shown that the utility of ULF wave Eigenfrequencies in magnetic mapping by comparing the Eigenfrequencies observed in-situ with the latitudinal Eigenfrequency profile determined by ground magnetometers (Rae et al. 2014) to determine the relative locations of mapped spacecraft footpoints to auroral features. Although the spatial resolution of the latitudinal Eigenfrequency profile is quite sparse, and the technique requires the identification of Eigenfrequencies on the ground and in space, the distribution of ground-based magnetometers in and around the auroral zone reduces the need for a lowaltitude spacecraft overpass during times of interest.

\section{Summary and Future Advancements}

Since the turn of the century, there has been a major growth in both ground-based and magnetospheric observations, with numerous multi-spacecraft missions and multi-observatory 
Table 1 Summary of mesoscale auroral forms, their size, where they are observed, their potential magnetotail drivers and locations of these drivers

\begin{tabular}{|c|c|c|c|c|}
\hline Auroral form & Scale size & Auroral location & Potential driver & Driver location \\
\hline \multirow{3}{*}{$\begin{array}{l}\text { Poleward } \\
\text { boundary } \\
\text { intensification }\end{array}$} & \multirow[t]{3}{*}{$10 \mathrm{~s}-100 \mathrm{~s} \mathrm{~km}$} & \multirow{3}{*}{$\begin{array}{l}\text { Nightside, } \\
\text { poleward edge of } \\
\text { auroral oval }\end{array}$} & $\begin{array}{l}\text { Fast flows arrivals from } \\
\text { polar cap }\end{array}$ & \multirow{3}{*}{$\begin{array}{l}\text { Magnetotail } \\
\text { lobes/deep tail } \\
\text { plasma-sheet; }\end{array}$} \\
\hline & & & $\begin{array}{l}\text { Spontaneous or triggered } \\
\text { in current sheet near or at } \\
\text { OCB }\end{array}$ & \\
\hline & & & $\begin{array}{l}\text { Ionospheric plasma flows } \\
\text { across conductivity } \\
\text { gradient }\end{array}$ & \\
\hline \multirow[t]{3}{*}{$\begin{array}{l}\text { Auroral } \\
\text { streamer }\end{array}$} & \multirow[t]{3}{*}{$\begin{array}{l}\sim 10 \mathrm{~s} \mathrm{~km} \mathrm{~s} \\
\text { across, } \\
\text { stretching } \\
\text { across the } \\
\text { auroral oval }\end{array}$} & \multirow[t]{3}{*}{$\begin{array}{l}\text { Nightside auroral } \\
\text { oval, stretching } \\
\text { from poleward to } \\
\text { equatorward edge }\end{array}$} & $\begin{array}{l}\text { Magnetotail fast plasma } \\
\text { flow/depleted plasma } \\
\text { channel within } \\
\text { plasma-sheet }\end{array}$ & $\begin{array}{l}\text { Magnetotail } \\
\text { plasma-sheet }\end{array}$ \\
\hline & & & $\begin{array}{l}\text { Possible scattering of } \\
\text { plasma-sheet particles by } \\
\text { whistler-mode chorus }\end{array}$ & $\begin{array}{l}\text { Magnetotail } \\
\text { plasma-sheet }\end{array}$ \\
\hline & & & $\begin{array}{l}\text { Monoenergetic electron } \\
\text { acceleration in upward } \\
\text { FAC }\end{array}$ & $\begin{array}{l}\text { Altitudes of a } \\
\text { few } R_{E}\end{array}$ \\
\hline \multirow[t]{3}{*}{$\begin{array}{l}\text { Omega bands } \\
\text { and torches }\end{array}$} & \multirow{3}{*}{$\begin{array}{l}\sim 200-500 \mathrm{~km} \\
\text { wide and } \\
\text { stretching } \\
\text { across the } \\
\text { auroral oval }\end{array}$} & \multirow{3}{*}{$\begin{array}{l}\text { Dawn side, } \\
\text { equatorward } \\
\text { portion of } \\
\text { expanded auroral } \\
\text { oval }\end{array}$} & $\begin{array}{l}\text { Kelvin-Helmholtz } \\
\text { instability }\end{array}$ & \multirow{3}{*}{$\begin{array}{l}\text { Near-Earth } \\
\text { magnetotail, } \\
\sim 7-12 \mathrm{R}_{\mathrm{E}}\end{array}$} \\
\hline & & & $\begin{array}{l}\text { Hybrid Kelvin- } \\
\text { Helmholtz/Rayleigh- } \\
\text { Taylor instability }\end{array}$ & \\
\hline & & & $\begin{array}{l}\text { May results from } \\
\text { injections associated with } \\
\text { streamers }\end{array}$ & \\
\hline \multirow[t]{2}{*}{ Auroral beads } & \multirow{2}{*}{$\begin{array}{l}1-500 \mathrm{~km}, \\
\text { typically } \\
\text { observed at } \\
\sim 100 \mathrm{~km} \\
\text { scales }\end{array}$} & \multirow{2}{*}{$\begin{array}{l}\text { Nightside, within } \\
\text { auroral oval } \\
\text { normally on } \\
\text { pre-existing quiet } \\
\text { arc }\end{array}$} & Ballooning instabilities & \multirow{2}{*}{$\begin{array}{l}\text { Near-Earth } \\
\text { magnetotail, } \\
10-12 \mathrm{R}_{\mathrm{E}}\end{array}$} \\
\hline & & & $\begin{array}{l}\text { Cross-tail current } \\
\text { instabilities }\end{array}$ & \\
\hline \multirow[t]{3}{*}{$\begin{array}{l}\text { Giant } \\
\text { undulations }\end{array}$} & \multirow[t]{3}{*}{$200-900 \mathrm{~km}$} & \multirow{3}{*}{$\begin{array}{l}\text { Equatorward } \\
\text { edge of dusk } \\
\text { auroral oval }\end{array}$} & $\begin{array}{l}\text { Kelvin Helmholtz } \\
\text { instability }\end{array}$ & \multirow{3}{*}{$\begin{array}{l}\text { Inner } \\
\text { magnetosphere/ } \\
\text { plasmapause }\end{array}$} \\
\hline & & & $\begin{array}{l}\text { Shear-flow ballooning } \\
\text { instability }\end{array}$ & \\
\hline & & & $\begin{array}{l}\text { Magnetospheric source of } \\
\text { SAPS }\end{array}$ & \\
\hline $\begin{array}{l}\text { Auroral bulge } \\
\text { (for context but } \\
\text { not covered in } \\
\text { this review) }\end{array}$ & $\begin{array}{l}\text { Up to } 10^{\circ} \\
\text { latitude and } \\
\text { several hours of } \\
\text { MLT }\end{array}$ & $\begin{array}{l}\text { Activated part of } \\
\text { nightside auroral } \\
\text { oval }\end{array}$ & $\begin{array}{l}\text { Dipolarized part of } \\
\text { magnetic field } \\
\text { configuration associated } \\
\text { with intense reconnection } \\
\text { and SCW }\end{array}$ & $\begin{array}{l}\text { Tail plasma } \\
\text { sheet earthward } \\
\text { of near-Earth } \\
\text { neutral line }\end{array}$ \\
\hline
\end{tabular}

programmes providing observations across multiple solar cycles. These datasets have already provided insights into the source and drivers of a range of meso-scale auroral forms, as laid out in this review and summarised in Table 1. However, multi-spacecraft missions, 
such as Cluster and THEMIS, have largely observed processes beyond $10 \mathrm{R}_{\mathrm{E}}$, corresponding to the source region of auroral streamers, while low-altitude missions, such as FAST and Swarm, provide snapshots of plasma conditions just above the ionosphere but not always with auroral observations for context. The implication of the results reported in this review is that the transition region between stretched tail plasma sheet region and dipole-like the inner magnetosphere, ranging from the plasmapause out to $\sim 12 \mathrm{R}_{\mathrm{E}}$ is now a key region to observe in order to understand the mechanisms that drive many dynamic meso-scale auroral forms.

Many of the meso-scale auroral forms discussed here have been linked with a variety of plasma instabilities in the magnetotail: PBIs and streamers are linked to reconnection and its outflows; auroral beads are linked to ballooning or current instabilities; omega bands, torches and giant undulations are linked to Kelvin-Helmholtz-based or shear flow ballooning instabilities. In order to understand the underlying physics, it is imperative that we understand the scales in the magnetosphere on which these instabilities act in order to provide measurements on the necessary time and spatial scales. Furthermore, understanding the growth rates of the auroral signatures of these instabilities may help to constrain the plasma conditions required for their formation. Quantitative comparisons of the growth rates, scale sizes and plasma conditions will then reveal the underlying physical processes. Some of these necessary observations may already exist within the repositories of current and past missions, while as others may need new missions that can provide observations across multiple scales in the inner magnetosphere in conjunction with auroral and auroral plasma observations from low-Earth orbiting spacecraft. Ultimately, a global magnetospheric view will be needed to complement a global aurora view and make direct observations of plasma motions and instabilities.

Acknowledgements The authors thank the International Space Science Institute (ISSI) for supporting a workshop on Auroral Physics and the workshop convenors (D.J. Knudsen, J. Borovsky, T. Karlsson, R. Kataoka, N. Partamies, R. von Steiger) and participants for useful discussions around this topic. CF was supported by a NERC Independent Research Fellowship NE/N014480/1 and STFC Consolidated Grant ST/S000240/1. Y.N. was supported by NASA grant NNX17AL22G and 80NSSC18K0657, NSF grants AGS1907698, AGS-1737823, and AFOSR FA9559-16-1-0364.

Publisher's Note Springer Nature remains neutral with regard to jurisdictional claims in published maps and institutional affiliations.

Open Access This article is licensed under a Creative Commons Attribution 4.0 International License, which permits use, sharing, adaptation, distribution and reproduction in any medium or format, as long as you give appropriate credit to the original author(s) and the source, provide a link to the Creative Commons licence, and indicate if changes were made. The images or other third party material in this article are included in the article's Creative Commons licence, unless indicated otherwise in a credit line to the material. If material is not included in the article's Creative Commons licence and your intended use is not permitted by statutory regulation or exceeds the permitted use, you will need to obtain permission directly from the copyright holder. To view a copy of this licence, visit http://creativecommons.org/licenses/by/4.0/.

\section{References}

A.T. Aikio, H. Vanhamäki, A.B. Workayehu, I.I. Virtanen, K. Kauristie, L. Juusola et al., Swarm satellite and EISCAT radar observations of a plasma flow channel in the auroral oval near magnetic midnight. J. Geophys. Res. Space Phys. 123, 5140-5158 (2018)

S.I. Akasofu, A study of auroral displays photographed from the DMSP-2 satellite and from the Alaska meridian chain of stations. Space Sci. Rev. 16, 617 (1974). https://doi.org/10.1007/BF00182598

S.I. Akasofu, Recent progress in studies of DMSP auroral photographs. Space Sci. Rev. 19, 169 (1976). https://doi.org/10.1007/BF00215692 
S.-I. Akasofu, D.S. Kimball, The dynamics of the aurora, 1. Instabilities of the aurora. J. Atmos. Terr. Phys. 26, 205 (1964)

S.-I. Akasofu, E.W. Hones Jr., M.D. Montgomery, S.J. Bame, S. Singer, Association of magnetotail phenomena with visible auroral features. J. Geophys. Res. 76, 5985-6003 (1971)

O. Amm, K. Kauristie, Ionospheric signatures of bursty bulk flows. Surv. Geophys. 23, 1-32 (2002)

O. Amm, A. Pajunpää, U. Brandström, Spatial distribution of conductances and currents associated with a north-south auroral form during a multiple-substorm period. Ann. Geophys. 17, 1385-1396 (1999). https://doi.org/10.1007/s00585-999-1385-6

O. Amm, R. Nakamura, T. Takada, K. Kauristie, H.U. Frey, C.J. Owen, A. Aikio, R. Kuula, Observations of an auroral streamer in a double oval configuration. Ann. Geophys. 29, 701-716 (2011). https://doi.org/ 10.5194/angeo-29-701-2011

V.A. Andreeva, N.A. Tsyganenko, Reconstructing the magnetosphere from data using radial basis functions. J. Geophys. Res. Space Phys. 121, 2249-2263 (2016). https://doi.org/10.1002/2015JA022242

V. Angelopoulos, W. Baumjohann, C.F. Kennel, F.V. Coroniti, M.G. Kivelson, R. Pellat, R.J. Walker, H. Lühr, G. Paschmann, Bursty bulk flows in the inner central plasma sheet. J. Geophys. Res. 97(A4), 4027-4039 (1992). https://doi.org/10.1029/91JA02701

W.E. Archer, D.J. Knudsen, J.K. Burchill, B. Jackel, E. Donovan, M. Connors, L. Juusola, Birkeland current boundary flows. J. Geophys. Res. Space Phys. 122, 4617-4627 (2017). https://doi.org/10.1002/ 2016JA023789

D.G. Baishev, E.S. Barkova, S.I. Solovyev, K. Yumoto, M.J. Engebretson, A.V. Koustov, Formation of largescale giant undulations at the equatorial boundary of diffuse aurora and Pc5 magnetic pulsations during the January 14, 1999 magnetic storm, in Proceedings of the Fifth International Conference on Substorms, ed. by A. Wilson. Eur. Space Agency Spec. Publ., vol. ESA SP-443 (2000), pp. 427-430

D.G. Baishev, E.S. Barkova, K. Yumoto, Optical observations of large-scale undulations in the 23rd cycle of solar activity. Geomagn. Aeron. 52(2), 197-203 (2012). https://doi.org/10.1134/s0016793212020028

J. Birn, M. Hesse, The substorm current wedge in MHD simulations. J. Geophys. Res. Space Phys. 118, 3364-3376 (2013). https://doi.org/10.1002/jgra.50187

J. Birn, J. Raeder, Y.L. Wang, R.A. Wolf, M. Hesse, On the propagation of bubbles in the geomagnetic tail. Ann. Geophys. 22, 1773-1786 (2004). https://doi.org/10.5194/angeo-22-1773-2004

J. Birn, V.G. Merkin, M.I. Sitnov, A. Otto, MHD stability of magnetotail configurations with a Bz hump. J. Geophys. Res. Space Phys. 123, 3477-3492 (2018). https://doi.org/10.1029/2018JA025290

J.E. Borovsky, D.T. Welling, M.F. Thomsen, M.H. Denton, Long-lived plasmaspheric drainage plumes: where does the plasma come from? J. Geophys. Res. Space Phys. 119, 6496-6520 (2014). https://doi.org/10.1002/2014JA020228

G. Branduardi-Raymont, C. Wang, A novel and global way to explore solar-terrestrial relationships: SMILE. Cospar Inf. Bull. 200, 32-39 (2017)

G. Branduardi-Raymont, S.F. Sembay, J.P. Eastwood et al., Exp. Astron. 33, 403 (2012). https://doi.org/ 10.1007/s10686-011-9239-0

W.A. Bristow, D.L. Hampton, A. Otto, High-spatial-resolution velocity measurements derived using Local Divergence-Free Fitting of SuperDARN observations. J. Geophys. Res. Space Phys. 121(2), 1349-1361 (2016)

T.V. Brito, S.K. Morley, Improving empirical magnetic field models by fitting to in situ data using an optimized parameter approach. Space Weather 15, 1628-1648 (2017). https://doi.org/10.1002/ 2017SW001702

S. Buchert, G. Haerendel, W. Baumjohann, A model for the electric fields and currents during a strong Ps 6 pulsation event. J. Geophys. Res. 95(A4), 3733-3743 (1990). https://doi.org/10.1029/ JA095iA04p03733

N.A. Case, A. Grocott, S.E. Milan, T. Nagai, J.P. Reistad, An analysis of magnetic reconnection events and their associated auroral enhancements. J. Geophys. Res. Space Phys. 122, 2922-2935 (2017). https://doi.org/10.1002/2016JA023586

C.X. Chen, R.A. Wolf, Interpretation of high-speed flows in the plasma sheet. J. Geophys. Res. 98(A12), 21409-21419 (1993). https://doi.org/10.1029/93JA02080

C.Z. Cheng, A.T.Y. Lui, Kinetic ballooning instability for substorm onset and current disruption observed by AMPTE/CCE. Geophys. Res. Lett. 25, 4091-4094 (1998). https://doi.org/10.1029/1998GL900093

C.Z. Cheng, S. Zaharia, MHD ballooning instability in the plasma sheet. Geophys. Res. Lett. 31, L06809 (2004). https://doi.org/10.1029/2003GL018823

$\mathrm{X}$. Chu et al., Development and validation of inversion technique for substorm current wedge using ground magnetic field data. J. Geophys. Res. Space Phys. 119, 1909-1924 (2014). https://doi.org/10.1002/ 2013JA019185

M. Connors, G. Rostoker, Source mechanisms for morning auroral features. Geophys. Res. Lett. 20(15), 1535-1538 (1993). https://doi.org/10.1029/93g101594 
O. de la Beaujardière, L.R. Lyons, J.M. Ruohoniemi, E. Friis-Christensen, C. Danielsen, F.J. Rich, P.T. andNewell, Quiet-time intensifications along the poleward auroral boundary near midnight. J. Geophys. Res. 99(A1), 287-298 (1994). https://doi.org/10.1029/93JA01947

E.F. Donovan, S. Mende, B. Jackel, H. Frey, M. Syrjäsuo, I. Voronkov, T. Trondsen, L. Peticolas, V. Angelopoulos, S. Harris, M. Greffen, M. Connors, The THEMIS all-sky imaging array-system design and initial results from the prototype imager. J. Atmos. Terr. Phys. 68, 1472-1487 (2006)

R.D. Elphinstone, D.J. Hearn, L.L. Cogger, J.S. Murphree, H. Singer, V. Sergeev, K. Mursula, D.M. Klumpar, G.D. Reeves, M. Johnson, S. Ohtani, T.A. Potemra, I. Sandahl, E. Nielsen, M. Persson, H. Opgenoorth, P.T. Newell, Y.I. Feldstein, Observations in the vicinity of substorm onset: implications for the substorm process. J. Geophys. Res. 100, 7937-7969 (1995). https://doi.org/10.1029/94JA02938

R.D. Elphinstone, J.S. Murphree, L.L. Cogger, What is a global auroral substorm? Rev. Geophys. 34, 169232 (1996)

D.H. Fairfield et al., Earthward flow bursts in the inner magnetotail and their relation to auroral brightening, AKR intensifications, geosynchronous particle injections and magnetic activity. J. Geophys. Res. 104, 355 (1999)

C. Forsyth, M. Lester, S.W.H. Cowley, I. Dandouras, A.N. Fazakerley, R.C. Fear, H.U. Frey, A. Grocott, A. Kadokura, E. Lucek, H. Rème, S.E. Milan, J. Watermann, Observed tail current systems associated with bursty bulk flows and auroral streamers during a period of multiple substorms. Ann. Geophys. 26, 167-184 (2008). https://doi.org/10.5194/angeo-26-167-2008

C. Forsyth, A.N. Fazakerley, I.J. Rae, C.E.J. Watt, K. Murphy, J.A. Wild, T. Karlsson, R. Mutel, C.J. Owen, R. Ergun, A. Masson, M. Berthomier, E. Donovan, H.U. Frey, J. Matzka, C. Stolle, Y. Zhang, In situ spatiotemporal measurements of the detailed azimuthal substructure of the substorm current wedge. J. Geophys. Res. Space Phys. 119, 927-946 (2014). https://doi.org/10.1002/2013JA019302

C. Forsyth, I.J. Rae, J.C. Coxon, M.P. Freeman, C.M. Jackman, J. Gjerloev, A.N. Fazakerley, A new technique for determining Substorm Onsets and Phases from Indices of the Electrojet (SOPHIE). J. Geophys. Res. Space Phys. 120, 10,592-10,606 (2015). https://doi.org/10.1002/2015JA021343

J.C. Foster, W.J. Burke, SAPS: a new categorization for sub-auroral electric fields. Eos Trans. AGU 83(36), 393-394 (2002). https://doi.org/10.1029/2002EO000289

E. Friedrich, J.C. Samson, I. Voronkov, Ground-based observations and plasma instabilities in auroral substorms, wave-like formations observed in aurora during substorm onset. Phys. Plasmas 8(4), 1104-1110 (2001). https://doi.org/10.1063/1.1355678

C. Gabrielse, V. Angelopoulos, A. Runov, D.L. Turner, The effects of transient, localized electric fields on equatorial electron acceleration and transport toward the inner magnetosphere. J. Geophys. Res. 117, A10213 (2012). https://doi.org/10.1029/2012JA017873

B. Gallardo-Lacourt, Y. Nishimura, L.R. Lyons, J.M. Ruohoniemi, E. Donovan, V. Angelopoulos, K.A. McWilliams, N. Nishitani, Ionospheric flow structures associated with auroral beading at substorm auroral onset. J. Geophys. Res. Space Phys. 119, 9150-9159 (2014a). https://doi.org/10.1002/ 2014JA020298

B. Gallardo-Lacourt, Y. Nishimura, L.R. Lyons, S. Zou, V. Angelopoulos, E. Donovan, et al., Coordinated SuperDARN THEMIS ASI observations of mesoscale flow bursts associated with auroral streamers. J. Geophys. Res. Space Phys. 119, 142-150 (2014b). https://doi.org/10.1002/2013JA019245

B. Gallardo-Lacourt, Y. Nishimura, L.R. Lyons, E.V. Mishin, J.M. Ruohoniemi, E.F. Donovan, V. Angelopoulos, N. Nishitani, Influence of auroral streamers on rapid evolution of ionospheric SAPS flows. J. Geophys. Res. Space Phys. 122, 12,406-12,420 (2017). https://doi.org/10.1002/2017JA024198

A. Grocott, T.K. Yeoman, R. Nakamura, S.W.H. Cowley, H.U. Frey, H. Rème, B. Klecker, Multi-instrument observations of the ionospheric counterpart of a bursty bulk flow in the near-Earth plasma sheet. Ann. Geophys. 22, 1-15 (2004)

M.G. Henderson, Implications of Viking Imager Results for Substorm Models. PhD Thesis, Department of Physics and Astronomy, University of Calgary (1994)

M.G. Henderson, Observational evidence for an inside-out substorm onset scenario. Ann. Geophys. 27, 21292140 (2009). https://doi.org/10.5194/angeo-27-2129-2009

M.G. Henderson, Recurrent embedded substorms during the 19 October 1998 GEM storm. J. Geophys. Res. Space Phys. 121, 7847-7859 (2016). https://doi.org/10.1002/2015JA022014

M.G. Henderson, G.D. Reeves, J.S. Murphree, The activation of the dusk-side and the formation of northsouth aligned structures during substorms, in Proc. Second International Conference on Substorms (ICS-2), ed. by J.R. Kan, J.D. Craven, S.-I. Akasofu (1994), p. 37. Geophysical Institure, University of Alaska Fairbanks

M.G. Henderson, G.D. Reeves, J.S. Muphree, Are north-south aligned auroral structures an ionospheric manifestation of bursty bulk flows? Geophys. Res. Lett. 25, 3737-3740 (1998)

M.G. Henderson, L. Kepko, H.E. Spence, M. Connors, J.B. Sigwarth, L.A. Frank, H.J. Singer, K. Yumoto, The evolution of north-south aligned auroral forms into auroral torch structures: the genera- 
tion of omega bands and Ps6 pulsations via flow bursts, in Proc. Sixth Int. Conf. on Substorms, ed. by R.M. Winglee (University of Washington, Seattle, 2002), pp. 169-174. http://permalink.lanl.gov/ object/tr?what=info:lanl-repo/lareport/LA-UR-02-lanl-repo/lareport/LA-UR-3972

M.G. Henderson, E.F. Donovan, J.C. Foster, I.R. Mann, T.J. Immel, S.B. Mende, J.B. Sigwarth, Start-to-end global imaging of a sunward propagating, SAPS-associated giant undulation event. J. Geophys. Res. 115, A04210 (2010). https://doi.org/10.1029/2009JA014106

M.G. Henderson, Auroral substorms, poleward boundary activations, auroral streamers, omega bands, and onset precursor activity, in Auroral Phenomenology and Magnetospheric Processes: Earth and Other Planets, ed. by A. Keiling et al. Geophysical Monograph Series, vol. 197, (American Geophysical Union, Washington, 2012), pp. 39-54

M.G. Henderson, S.K. Morley, L.E. Kepko, SAPS-associated explosive brightening on the duskside: a new type of onset-like disturbance. J. Geophys. Res. Space Phys. 123, 197-210 (2018). https://doi.org/ 10.1002/2017JA024472

K. Hosokawa, S.E. Milan, M. Lester, A. Kadokura, N. Sato, G. Bjornsson, Large flow shears around auroral beads at substorm onset. Geophys. Res. Lett. 40, 4987-4991 (2013). https://doi.org/10.1002/grl.50958

A.J. Hull, M. Wilber, C.C. Chaston, J.W. Bonnell, J.P. McFadden, F.S. Mozer, M. Fillingim, M.L. Goldstein, Time development of field-aligned currents, potential drops, and plasma associated with an auroral poleward boundary intensification. J. Geophys. Res. Space Phys. 115, A06211 (2010). https://doi.org/ 10.1029/2009JA014651

K.-J. Hwang, M.L. Goldstein, E. Lee, J.S. Pickett, Cluster observations of multiple dipolarization fronts. J. Geophys. Res. 116, A00I32 (2011). https://doi.org/10.1029/2010JA015742

A. Ieda, D.H. Fairfield, T. Mukai, Y. Saito, S. Kokubun, K. Liou, C.-I. Meng, G.K. Parks, M.J. Brittnacher, Plasmoid ejection and auroral brightenings. J. Geophys. Res. 106(A3), 3845-3857 (2001). https:// doi.org/10.1029/1999JA000451

A. Ieda et al., Longitudinal association between magnetotail reconnection and auroral breakup based on Geotail and Polar observations. J. Geophys. Res. 113, A08207 (2008). https://doi.org/10.1029/ 2008JA013127

S.M. Imber, J.A. Slavin, H.U. Auster, V. Angelopoulos, A THEMIS survey of flux ropes and traveling compression regions: location of the near-Earth reconnection site during solar minimum. J. Geophys. Res. 116, A02201 (2011). https://doi.org/10.1029/2010JA016026

F. Jiang, M.G. Kivelson, R.J. Strangeway, K.K. Khurana, R. Walker, Ionospheric flow shear associated with the preexisting auroral arc: a statistical study from the FAST spacecraft data. J. Geophys. Res. Space Phys. 120, 5194-5213 (2015). https://doi.org/10.1002/2013JA019255

A.M. Jorgensen, H.E. Spence, T.J. Hughes, D. McDiarmid, A study of omega bands and Ps6 pulsations on the ground, at low altitude and at geostationary orbit. J. Geophys. Res. 104(A7), 14705-14715 (1999). https://doi.org/10.1029/1998JA900100

L. Juusola, N. Østgaard, E. Tanskanen, Statistics of plasma sheet convection. J. Geophys. Res. Space Phys. 116, A08201 (2011). https://doi.org/10.1029/2011JA016479

L. Juusola, M. Kubyshkina, R. Nakamura, T. Pitkänen, O. Amm, K. Kauristie, N. Partamies, H. Rème, K. Snekvik, D. Whiter, Ionospheric signatures of a plasma sheet rebound flow during a substorm onset. J. Geophys. Res. Space Phys. 118, 350-363 (2013). https://doi.org/10.1029/2012JA018132

N.M.E. Kalmoni, I.J. Rae, C.E.J. Watt, K.R. Murphy, C. Forsyth, C.J. Owen, Statistical characterization of the growth and spatial scales of the substorm onset arc. J. Geophys. Res. Space Phys. 120, 8503-8516 (2015). https://doi.org/10.1002/2015JA021470

N.M.E. Kalmoni, I.J. Rae, K.R. Murphy, C. Forsyth, C.E.J. Watt, C.J. Owen, Statistical azimuthal structuring of the substorm onset arc: implications for the onset mechanism. Geophys. Res. Lett. (2017). https://doi.org/10.1002/2016g1071826

N.M.E. Kalmoni, I.J. Rae, C.E.J. Watt, K.R. Murphy, M. Samara, R.G. Michell et al., A diagnosis of the plasma waves responsible for the explosive energy release of substorm onset. Nat. Commun. 9(1) (2018). https://doi.org/10.1038/s41467-018-07086-0

R. Kataoka, Y. Miyoshi, T. Sakanoi, A. Yaegashi, K. Shiokawa, Y. Ebihara, Turbulent microstructures and formation of folds in auroral breakup arc. J. Geophys. Res. 116, A00K02 (2011). https://doi.org/ 10.1029/2010JA016334

R.L. Kauffman, D.J. Larson, C. Lu, Mapping and distortions of auroral structures in the quiet magnetosphere. J. Geophys. Res. Space Phys. 95(A6), 7973-7994 (1990). https://doi.org/10.1029/JA095iA06p07973

K. Kauristie, V.A. Sergeev, O. Amm, M.V. Kubyshkina, J. Jussila, E. Donovan, K. Liou, Bursty bulk flow intrusion to the inner plasma sheet as inferred from auroral observations. J. Geophys. Res. 108(A1), 1040 (2003). https://doi.org/10.1029/2002JA009371

A. Keiling, K. Shiokawa, V. Uritsky, V. Sergeev, E. Zesta, L. Kepko, N. Ostgaard, Auroral signatures of the dynamic plasma sheet, in Auroral Phenomenology and Magnetospheric Processes: Earth and Other 
Planets, ed. by A. Keiling. Geophysical Monograph Series, vol. 197 (2013), pp. 317-335. American Geophysical Union

M.C. Kelley, Intense sheared flow as the origin of large-scale undulations of the edge of the diffuse aurora. J. Geophys. Res. 91(A3), 3225-3230 (1986). https://doi.org/10.1029/JA091iA03p03225

L. Kepko, E. Spanswick, V. Angelopoulos, E. Donovan, J. McFadden, K.-H. Glassmeier, J. Raeder, H.J. Singer, Equatorward moving auroral signatures of a flow burst observed prior to auroral onset. Geophys. Res. Lett. 36, L24104 (2009). https://doi.org/10.1029/2009GL041476

L. Kepko, R.L. McPherron, O. Amm, S. Apatenkov, W. Baumjohann, J. Birn, M. Lester, R. Nakamura, T.I. Pulkkinen, V. Sergeev, Substorm current wedge revisited. Space Sci. Rev. 190, 1-46 (2015). https://doi.org/10.1007/s11214-014-0124-9

K.H. Kim, K. Takahashi, D.H. Lee, P.R. Sutcliffe, K. Yumoto, Pi2 pulsations associated with poleward boundary intensifications during the absence of substorms. J. Geophys. Res. Space Phys. 110(A1) (2005). https://doi.org/10.1029/2004JA010780

S. Knight, Parallel electric fields. Planet. Space Sci. 21(5), 741-750 (1973). https://doi.org/10.1016/00320633(73)90093-7

M. Kubyshkina, V. Sergeev, N. Tsyganenko, V. Angelopoulos, A. Runov, E. Donovan, H. Singer, U. Auster, W. Baumjohann, Time-dependent magnetospheric configuration and breakup mapping during a substorm. J. Geophys. Res. 116, A00I27 (2011). https://doi.org/10.1029/2010JA015882

M. Kubyshkina, V.A. Sergeev, N.A. Tsyganenko, Y. Zheng, Testing efficiency of empirical, adaptive, and global MHD magnetospheric models to represent the geomagnetic field in a variety of conditions. Space Weather 17(5), 672-686 (2019). https://doi.org/10.1029/2019SW002157

J. Liang, E.F. Donovan, W.W. Liu, B. Jackel, M. Syrjäsuo, S.B. Mende, H.U. Frey, V. Angelopoulos, a. Connors, Intensification of preexisting auroral arc at substorm expansion phase onset: wave-like disruption during the first tens of seconds. Geophys. Res. Lett. 35, L17S19 (2008). https://doi.org/10.1029/ 2008GL033666

J. Liu, V. Angelopoulos, A. Runov, X.-Z. Zhou, On the current sheets surrounding dipolarizing flux bundles in the magnetotail: the case for wedgelets. J. Geophys. Res. Space Phys. 118, 2000-2020 (2013). https://doi.org/10.1002/jgra.50092

J. Liu, L.R. Lyons, W.E. Archer, B. Gallardo-Lacourt, Y. Nishimura, Y. Zou, et al., Flow shears at the poleward boundary of omega bands observed during conjunctions of Swarm and THEMIS ASI. Geophys. Res. Lett. 45, 1218-1227 (2018). https://doi.org/10.1002/2017GL076485

A.T.Y. Lui, Cross-field current instability for auroral bead formation in breakup arcs. Geophys. Res. Lett. 43, 6087-6095 (2016). https://doi.org/10.1002/2016GL069892

A.T.Y. Lui, C.-I. Meng, S. Ismail, Large amplitude undulations on the equatorward boundary of the diffuse aurora. J. Geophys. Res. 87(A4), 2385 (1982). https://doi.org/10.1029/ja087ia04p02385

A.T.Y. Lui, C.-L. Chang, A. Mankofsky, H.-K. Wong, D. Winske, A cross-field current instability for substorm expansions. J. Geophys. Res. 96, 11,389-11,401 (1991). https://doi.org/10.1029/91JA00892

K.A. Lynch, D. Hampton, M. Mella, B.Z. Zhang, H. Dahlgren, M. Disbrow, P.M. Kintner, M. Lessard, E. Lundberg, H.C. Stenbaek-Nielsen, Structure and dynamics of the nightside poleward boundary: sounding rocket and ground-based observations of auroral electron precipitation in a rayed curtain. J. Geophys. Res. Space Phys. 117 (2012). https://doi.org/10.1029/2012JA017691

L.R. Lyons, Geomagnetic disturbances: characteristics of, distinction between types, and relations to interplanetary conditions. J. Atmos. Sol.-Terr. Phys. 62(12), 1087-1114 (2000)

L.R. Lyons, R.L. Walterscheid, Generation of auroral omega bands by shear instability of the neutral winds. J. Geophys. Res. 90, 12321-12329 (1985)

L.R. Lyons, T. Nagai, G.T. Blanchard, J.C. Samson, T. Yamamoto, T. Mukai, et al., Association between Geotail plasma flows and auroral poleward boundary intensifications observed by CANOPUS photometers. J. Geophys. Res. 104(A3), 4485-4500 (1999). https://doi.org/10.1029/1998JA900140

L.R. Lyons, E. Zesta, Y. Xu, E.R. Sánchez, J.C. Samson, G.D. Reeves, J.M. Ruohoniemi, J.B. Sigwarth, Auroral poleward boundary intensifications and tail bursty flows: a manifestation of a large-scale ULF oscillation? J. Geophys. Res. 107(A11), 1352 (2002). https://doi.org/10.1029/2001JA000242

L.R. Lyons, Y. Nishimura, H.J. Kim, E. Donovan, V. Angelopoulos, G. Sofko, M. Nicolls, C. Heinselman, J.M. Ruohoniemi, N. Nishitani, Possible connection of polar cap flows to pre- and post-substorm onset PBIs and streamers. J. Geophys. Res. Space Phys. 116 (2011). https://doi.org/10.1029/2011JA016850

L.R. Lyons et al., Driving of strong nightside reconnection and geomagnetic activity by polar cap flows: application to CME shocks and possibly other situations. J. Atmos. Sol.-Terr. Phys. 177, 73-83 (2018)

R.L. McPherron, T.-S. Hsu, J. Kissinger, X. Chu, V. Angelopoulos, Characteristics of plasma flows at the inner edge of the plasma sheet. J. Geophys. Res. 116, A00I33 (2011). https://doi.org/10.1029/ 2010JA015923 
M.R. Mella, K.A. Lynch, D.L. Hampton, H. Dahlgren, P.M. Kintner, M. Lessard, D. Lummerzheim, E.T. Lundberg, M.J. Nicolls, H.C. Stenbaek-Nielsen, Sounding rocket study of two sequential auroral poleward boundary intensifications. J. Geophys. Res. Space Phys. 116, A00K18 (2011)

M. Mendillo, J. Baumgardner, J. Providakes, Ground based imaging of detached arcs, ripples in the diffuse aurora, and patches of $6300 \AA$ emission. J. Geophys. Res. 94, 5367-5381 (1989)

L.E. Montbriand, The proton aurora substorm, in The Radiating Atmosphere, ed. by B.M. McCormac (D. Reidel, Norwell, 1971), pp. 366-373

T. Motoba, M. Hirahara, High-resolution auroral acceleration signatures within a highly dynamic onset arc. Geophys. Res. Lett. 43, 1793-1801 (2016). https://doi.org/10.1002/2015GL067580

T. Motoba, K. Hosokawa, A. Kadokura, N. Sato, Magnetic conjugacy of northern and southern auroral beads. Geophys. Res. Lett. 39, L08108 (2012). https://doi.org/10.1029/2012GL051599

T. Motoba, K. Takahashi, A. Ukhorskiy, M. Gkioulidou, D.G. Mitchell, L.J. Lanzerotti, G.I. Korotova, E.F. Donovan, J.R. Wygant, C.A. Kletzing, W.S. Kurth, J.B. Blake, Link between premidnight second harmonic poloidal waves and auroral undulations: conjugate observations with a Van Allen Probe spacecraft and a THEMIS all-sky imager. J. Geophys. Res. Space Phys. 120, 1814-1831 (2015). https://doi.org/10.1002/2014JA020863

J.S. Murphree, M.L. Johnson, Clues to plasma processes based on Freja UV observations. Adv. Space Res. 18, 95-105 (1996)

K.R. Murphy, I.R. Mann, I.J. Rae, C.L. Waters, H.U. Frey, A. Kale, H.J. Singer, B.J. Anderson, H. andKorth, The detailed spatial structure of field-aligned currents comprising the substorm current wedge. J. Geophys. Res. Space Phys. 118, 7714-7727 (2013). https://doi.org/10.1002/2013JA018979

R. Nakamura, T. Oguti, T. Yamamoto, S. Kokubun, Equatorward and poleward expansion of the auroras during auroral substorms. J. Geophys. Res. 98(A4), 5743-5759 (1993). https://doi.org/10.1029/92JA02230

R. Nakamura, W. Baumjohann, R. Schödel, M. Brittnacher, V.A. Sergeev, M. Kubyshkina, T. Mukai, K. Liou, Earthward flow bursts, auroral streamers, and small expansions. J. Geophys. Res. 106, 10,791-10,802 (2001)

R. Nakamura et al., Spatial scale of high-speed flows in the plasma sheet observed by cluster. Geophys. Res. Lett. 31, L09804 (2004). https://doi.org/10.1029/2004GL019558

R. Nakamura, O. Amm, H. Laakso, N.C. Draper, M. Lester, A. Grocott, B. Klecker, I.W. McCrea, A. Balogh, H. Rème, M. André, Localized fast flow disturbance observed in the plasma sheet and in the ionosphere. Ann. Geophys. 23, 553-566 (2005). https://doi.org/10.5194/angeo-23-553-2005

A.V. Nikolaev, V.A. Sergeev, N.A. Tsyganenko, M.V. Kubyshkina, H. Opgenoorth, H. Singer, V. Angelopoulos, A quantitative study of magnetospheric magnetic field line deformation by a two-loop substorm current wedge. Ann. Geophys. 33, 505-517 (2015). https://doi.org/10.5194/angeo-33-505-2015

Y. Nishimura, L. Lyons, S. Zou, V. Angelopoulos, S. Mende, Substorm triggering by new plasma intrusion: THEMIS all-sky imager observations. J. Geophys. Res. 115, A07222 (2010a). https://doi.org/10.1029/ 2009JA015166

Y. Nishimura et al., Preonset time sequence of auroral substorms: coordinated observations by allsky imagers, satellites, and radars. J. Geophys. Res. 115, A00I08 (2010b). https://doi.org/10.1029/ 2010JA015832

Y. Nishimura, J. Bortnik, W. Li, R.M. Thorne, L.R. Lyons, V. Angelopoulos, S.B. Mende, J.W. Bonnell, O. Le Contel, C. Cully, R. Ergun, U. Auster, Identifying the driver of pulsating aurora. Science 330, 6000 (2010c). https://doi.org/10.1126/science.119318

Y. Nishimura, L.R. Lyons, V. Angelopoulos, T. Kikuchi, S. Zou, S.B. Mende, Relations between multiple auroral streamers, pre-onset thin arc formation, and substorm auroral onset. J. Geophys. Res. 116, A09214 (2011). https://doi.org/10.1029/2011JA016768

Y. Nishimura, L.R. Lyons, X. Xing, V. Angelopoulos, E.F. Donovan, S.B. Mende, J.W. Bonnell, U. Auster, Identifying the magnetotail source region leading to preonset poleward boundary intensifications. J. Geophys. Res. Space Phys. 118, 4335-4340 (2013a). https://doi.org/10.1002/jgra.50407

Y. Nishimura, L.R. Lyons, K. Shiokawa, V. Angelopoulos, E.F. Donovan, S.B. Mende, Substorm onset and expansion phase intensification precursors seen in polar cap patches and arcs. J. Geophys. Res. Space Phys. 118, 2034-2042 (2013b). https://doi.org/10.1002/jgra.50279

Y. Nishimura, L.R. Lyons, X. Xing, V. Angelopoulos, E.F. Donovan, S.B. Mende, J.W. Bonnell, U. Auster, Tail reconnection region versus auroral activity inferred from conjugate ARTEMIS plasma sheet flow and auroral observations. J. Geophys. Res. Space Phys. 118, 5758-5766 (2013c). https://doi.org/ 10.1002/jgra.50549

Y. Nishimura et al., Day-night coupling by a localized flow channel visualized by polar cap patch propagation. Geophys. Res. Lett. 41(11), 3701-3709 (2014)

Y. Nishimura, J. Yang, P.L. Pritchett, F.V. Coroniti, E.F. Donovan, L.R. Lyons, R.A. Wolf, V. Angelopoulos, S.B. Mende, Statistical properties of substorm auroral onset beads/rays. J. Geophys. Res. Space Phys. 121, 8661-8676 (2016). https://doi.org/10.1002/2016JA022801 
N. Nishitani, G. Hough, M.W.J. Scourfield, Spatial and temporal characteristics of giant undulations. Geophys. Res. Lett. 21, 2673-2676 (1994)

T. Oguti, Hydrogen emission and electron aurora at the onset of the auroral breakup. J. Geophys. Res. 78(31), 7543-7547 (1973). https://doi.org/10.1029/JA078i031p07543

T. Oguti, Tv observations of auroral arcs, in Physics of Auroral Arc Formation, ed. by e.S. Akasofu, J. Kan (1981). https://doi.org/10.1029/GM025p0031

S. Ohtani, A. Yoshikawa, The initiation of the poleward boundary intensification of auroral emission by fast polar cap flows: a new interpretation based on ionospheric polarizarion. J. Geophys. Res. Space Phys. 121, 10910-10928 (2016). https://doi.org/10.1002/2016JA023143

S. Ohtani, T. Motoba, J.W. Gjerloev, J.M. Ruohoniemi, E.F. Donovan, A. Yoshikawa, Longitudinal development of Poleward Boundary Intensifications (PBIs) of auroral emission. J. Geophys. Res. Space Phys. 123(11), 9005-9021 (2018)

H.J. Opgenoorth, J. Oksman, K.U. Kaila, E. Nielsen, W. Baumjohann, Characteristics of eastward drifting omega bands in the morning sector of the auroral oval. J. Geophys. Res. 88(A11), 9171-9185 (1983). https://doi.org/10.1029/JA088iA11p09171

H.J. Opgenoorth, M.A.L. Persson, T.I. Pulkkinen, R.J. Pellinen, Recovery phase of magnetospheric substorms and its association with morning-sector aurora. J. Geophys. Res. 99(A3), 4115-4129 (1994). https://doi.org/10.1029/93JA01502

M. Palmroth, I. Honkonen, A. Sandroos, Preliminary testing of global hybrid-Vlasov simulation: magnetosheath and cusps under northward interplanetary magnetic field. J. Atmos. Sol.-Terr. Phys. 99, 41-46 (2013). https://doi.org/10.1016/j.jastp.2012.09.013

M. Palmroth, U. Ganse, Y. Pfau-Kempf, M. Battarbee, L. Turc, T. Brito et al., Vlasov methods in space physics and astrophysics. Living Rev. Comput. Astrophys. 4(1) (2018). https://doi.org/10.1007/ s41115-018-0003-2

N. Partamies, J.M. Weygand, L. Juusola, Statistical study of auroral omega bands. Ann. Geophys. 35, 10691083 (2017). https://doi.org/10.5194/angeo-35-1069-2017

G. Paschmann, S. Haaland, R. Treumann (eds.), Auroral Plasma Physics (2003). Springer Netherlands. https://doi.org/10.1007/978-94-007-1086-3.

S. Perraut et al., Current-driven electromagnetic ion cyclotron instability at substorm onset. J. Geophys. Res. 105, 21,097-21,107 (2000). https://doi.org/10.1029/2000JA900059

T. Pitkänen, A.T. Aikio, O. Amm, K. Kauristie, H. Nilsson, K.U. Kaila, EISCAT-cluster observations of quiet-time near-Earth magnetotail fast flows and their signatures in the ionosphere. Ann. Geophys. 29, 299-319 (2011). https://doi.org/10.5194/angeo-29-299-2011

T. Pitkanen, A.T. Aikio, L. Juusola, Observations of polar cap flow channel and plasma sheet flow bursts during substorm expansion. J. Geophys. Res. Space Phys. 118(2), 774-784 (2013)

P.L. Pritchett, Externally driven magnetic reconnection in the presence of a normal magnetic field. J. Geophys. Res. 110, A05209 (2005). https://doi.org/10.1029/2004JA010948

P.L. Pritchett, F.V. Coroniti, A kinetic ballooning/interchange instability in the magnetotail. J. Geophys. Res. 115, A06301 (2010). https://doi.org/10.1029/2009JA014752

P.L. Pritchett, F.V. Coroniti, Structure and consequences of the kinetic ballooning/interchange instability in the magnetotail. J. Geophys. Res. Space Phys. 118, 146-159 (2013). https://doi.org/10.1029/ 2012JA018143

P.L. Pritchett, F.V. Coroniti, Y. Nishimura, The kinetic ballooning/interchange instability as a source of dipolarization fronts and auroral streamers. J. Geophys. Res. Space Phys. 119(6), 4723-4739 (2014)

J.F. Provadakes, M.C. Kelley, W.E. Swartz, M. Mendillo, Radar and optical measurements of ionospheric processes associated with intense subauroral electric fields. J. Geophys. Res. 94, 5350-5366 (1989)

T.I. Pulkkinen, R.J. Pellinen, H.E.J. Koskinen, H.J. Opgenoorth, J.S. Murphree, V. Petrov, A. Zaitzev, E. Friis-Christensen, Auroral signatures of substorm recovery phase: a case study, in In Magnetospheric Substorms, ed. by J.R. Kan et al.. Geophys. Monogr. Ser., vol. 64 (AGU, Washington, 1991), pp. 333341

I.J. Rae et al., Near-Earth initiation of a terrestrial substorm. J. Geophys. Res. 114, A07220 (2009). https:// doi.org/10.1029/2008JA013771

I.J. Rae, C.E.J. Watt, I.R. Mann, K.R. Murphy, J.C. Samson, K. Kabin, V. Angelopoulos, Optical characterization of the growth and spatial structure of a substorm onset arc. J. Geophys. Res. 115, A10222 (2010). https://doi.org/10.1029/2010JA015376

I.J. Rae, C.E.J. Watt, K.R. Murphy, H.U. Frey, L.G. Ozeke, D.K. Milling, I.R. Mann, The correlation of ULF waves and auroral intensity before, during and after substorm expansion phase onset. J. Geophys. Res. 117, A08213 (2012). https://doi.org/10.1029/2012JA017534

I.J. Rae, K.R. Murphy, C.E.J. Watt, G. Rostoker, R. Rankin, I.R. Mann, C.R. Hodgson, H.U. Frey, A.W. Degeling, C. Forsyth, Field line resonances as a trigger and a tracer for substorm onset. J. Geophys. Res. Space Phys. 119, 5343-5363 (2014). https://doi.org/10.1002/2013JA018889 
I.J. Rae, K.R. Murphy, C.E.J. Watt, A.J. Halford, I.R. Mann, L.G. Ozeke, et al., The role of localized compressional ultra-low frequency waves in energetic electron precipitation. J. Geophys. Res. Space Phys. 123, 1900-1914 (2018). https://doi.org/10.1002/2017JA024674

G. Rostoker, J.C. Samson, Can substorm expansive phase effects and low frequency Pc magnetic pulsations be attributed to the same source mechanism? Geophys. Res. Lett. 11(3), 271-274 (1984). https://doi.org/10.1029/g1011i003p00271

G. Rostoker, A.T.Y. Lui, C.D. Anger, J.S. Murphree, North-south structures in the midnight sector auroras as viewed by the Viking imager. Geophys. Res. Lett. 14, 407-410 (1987)

A. Runov, V. Angelopoulos, M.I. Sitnov, V.A. Sergeev, J. Bonnell, J.P. McFadden, D. Larson, K.-H. Glassmeier, U. Auster, THEMIS observations of an earthward-propagating dipolarization front. Geophys. Res. Lett. 36, L14106 (2009). https://doi.org/10.1029/2009GL038980

T. Saito, Space Sci. Rev. 21, 427 (1978). https://doi.org/10.1007/BF00173068

K. Sakaguchi, K. Shiokawa, A. Ieda, R. Nomura, A. Nakajima, M. Greffen, E. Donovan, I.R. Mann, H. Kim, M. Lessard, Fine structures and dynamics in auroral initial brightening at substorm onsets. Ann. Geophys. 27(2), 623-630 (2009). https://doi.org/10.5194/angeo-27-623-2009

P.E. Sandholt, C.J. Farrugia, M. Lester, S. Cowley, S. Milan, W.F. Denig, B. Lybekk, E. Trondsen, V. Vorobjev, Multistage substorm expansion: Auroral dynamics in relation to plasma sheet particle injection, precipitation, and plasma convection. J. Geophys. Res. Space Phys. 107(A11) (2002). https://doi.org/10.1029/2001JA900116

V.A. Sergeev, Ionospheric signatures of magnetospheric particle acceleration in substorms - how to decode them? in Proceedings of the 6th International Conference on Substorms, ed. by R.M. Winglee (Univ. of Washington, Seattle, 2002), pp. 39-46

V.A. Sergeev, Bursty Bulk Flows and Their Ionospheric Footprints, Multiscale Processes in the Earth's Magnetosphere: From Interball to Cluster (2005), pp. 289-297. Springer Netherlands

V.A. Sergeev, V. Angelopoulos, J.T. Gosling, C.A. Cattell, C.T. Russell, Detection of localized, plasmadepleted flux tubes or bubbles in the midtail plasma sheet. J. Geophys. Res. 101(A5), 10817-10826 (1996). https://doi.org/10.1029/96JA00460

V.A. Sergeev, K. Liou, C.-I. Meng, P.T. Newell, M. Brittnacher, G. Parks, G.D. Reeves, Development of auroral streamers in association with localized impulsive injections to the inner magnetotail. Geophys. Res. Lett. 26, 417-420 (1999)

V.A. Sergeev, J.-A. Sauvaud, D. Popescu, R.A. Kovrazhkin, K. Liou, P.T. Newell, M. Brittnacher, G. Parks, R. Nakamura, T. Mukai, Multiple-spacecraft observation of a narrow transient plasma jet in the Earth's plasma sheet. Geophys. Res. Lett. 27, 851-854 (2000)

V.A. Sergeev, K. Liou, P.T. Newell, S.I. Ohtani, M.R. Hairston, F. Rich, Auroral streamers: characteristics of associated precipitation, convection and field-aligned currents. Ann. Geophys. 22, 537-548 (2004)

V.A. Sergeev, K. Liou, S.-I. Ohtani, M. Hairston, M. Thomsen, Narrow plasma streams as a candidate to populate the inner magnertosphere, in The Inner Magnetosphere: Physics and Modeling, ed. by T.I. Pulkkinen, N.A. Tsyganenko, R.H.W. Friedel. Geophys. Monogr., vol. 155 (2005), pp. 55-60. https://doi.org/10.1029/155GM07

V.A. Sergeev, V. Angelopoulos, R. Nakamura, Recent advances in understanding substorm dynamics. Geophys. Res. Lett. 39, L05101 (2012). https://doi.org/10.1029/2012GL050859

V.A. Sergeev, I.A. Chernyaev, V. Angelopoulos, A.V. Runov, R. Nakamura, Stopping flow bursts and their role in the generation of the substorm current wedge. Geophys. Res. Lett. 41, 1106-1112 (2014). https://doi.org/10.1002/2014GL059309

I.G. Shevchenko, V. Sergeev, M. Kubyshkina, V. Angelopoulos, K.H. Glassmeier, H.J. Singer, Estimation of magnetosphere-ionosphere mapping accuracy using isotropy boundary and THEMIS observations. J. Geophys. Res. 115, A11206 (2010). https://doi.org/10.1029/2010JA015354

Y. Shi, E. Zesta, Global-scale ionospheric flow and aurora precursors of auroral substorms: coordinated SuperDARN and IMAGE/WIC observations. J. Geophys. Res. Space Phys. 119, 4860-4871 (2014). https://doi.org/10.1002/2013JA019175

Y. Shi, E. Zesta, L.R. Lyons, J. Yang, A. Boudouridis, Y.S. Ge, J.M. Ruohoniemi, S. Mende, Two-dimensional ionospheric flow pattern associated with auroral streamers. J. Geophys. Res. 117, A02208 (2012). https://doi.org/10.1029/2011JA017110

K. Shiokawa, G. Haerendel, W. Baumjohann, Azimuthal pressure gradient as driving force of substorm currents. Geophys. Res. Lett. 25(7), 959-962 (1998). https://doi.org/10.1029/98g100540

D.G. Sibeck, R. Allen, H. Aryan et al., Space Sci. Rev. 214, 79 (2018). https://doi.org/10.1007/s11214018-0504-7

M.I. Sitnov, N.A. Tsyganenko, A.Y. Ukhorskiy, P.C. Brandt, Dynamical data-based modeling of the stormtime geomagnetic field with enhanced spatial resolution. J. Geophys. Res. 113, A07218 (2008). https:// doi.org/10.1029/2007JA013003 
M.I. Sitnov, N. Buzulukova, M. Swisdak, V.G. Merkin, T.E. Moore, Spontaneous formation of dipolarization fronts and reconnection onset in the magnetotail. Geophys. Res. Lett. 40(1), 22-27 (2013). https://doi.org/10.1029/2012GL054701

M. Sitnov, J. Birn, B. Ferdousi et al., Space Sci. Rev. 215, 31 (2019). https://doi.org/10.1007/s11214019-0599-5

D.J. Southwood, The hydromagnetic stability of the magnetospheric boundary. Planet. Space Sci. 16, 587 (1968)

G.K. Stephens, M.I. Sitnov, H. Korth, N.A. Tsyganenko, S. Ohtani, M. Gkioulidou, A.Y. Ukhorskiy, Global empirical picture of magnetospheric substorms inferred from multimission magnetometer data. J. Geophys. Res. Space Phys. 124, 1085-1110 (2019). https://doi.org/10.1029/2018JA025843

W.J. Sun, S.Y. Fu, G.K. Parks, J. Liu, Z.H. Yao, Q.Q. Shi, Q.-G. Zong, S.Y. Huang, Z.Y. Pu, T. Xiao, Field-aligned currents associated with dipolarization fronts. Geophys. Res. Lett. 40, 4503-4508 (2013). https://doi.org/10.1002/grl.50902

V.R. Tagirov, Auroral torch structures: results of optical observations. J. Atmos. Sol.-Terr. Phys. 55(14), 1775-1787 (1993). https://doi.org/10.1016/0021-9169(93)90144-n

N.A. Tsyganenko, Data-based modelling of the Earth's dynamic magnetosphere: a review. Ann. Geophys. 31, 1745-1772 (2013). https://doi.org/10.5194/angeo-31-1745-2013

N.A. Tsyganenko, V.A. Andreeva, A forecasting model of the magnetosphere driven by an optimal solar wind coupling function. J. Geophys. Res. Space Phys. 120, 8401-8425 (2015). https://doi.org/ 10.1002/2015JA021641

N.A. Tsyganenko, V.A. Andreeva, An empirical RBF model of the magnetosphere parameterized by interplanetary and ground-based drivers. J. Geophys. Res. Space Phys. 121, 10,786-10,802 (2016). https://doi.org/10.1002/2016JA023217

A.F. Viñas, T.R. Madden, Shear flow-ballooning instability as a possible mechanism for hydromagnetic fluctuations. J. Geophys. Res. 91(A2), 1519-1528 (1986). https://doi.org/10.1029/JA091iA02p01519

I. Voronkov, R. Rankin, P. Frycz, V.T. Tikhonchuk, J.C. Samson, Coupling of shear flow and pressure gradient instabilities. J. Geophys. Res. 102(A5), 9639-9650 (1997). https://doi.org/10.1029/97JA00386

I. Voronkov, E. Friedrich, J.C. Samson, Dynamics of the substorm growth phase as observed using CANOPUS and SuperDARN instruments. J. Geophys. Res. 104(A12), 28491-28505 (1999). https://doi.org/10.1029/1999JA900362

I.O. Voronkov, E.F. Donovan, B.J. Jackel, J.C. Samson, Large-scale vortex dynamics in the evening and midnight auroral zone: observations and simulations. J. Geophys. Res. 105, 18505-18518 (2000)

I.O. Voronkov, E.F. Donovan, J.C. Samson, Observations of the phases of the substorm. J. Geophys. Res. Space Phys. 108(A2) (2003). https://doi.org/10.1029/2002JA009314

A.D.M. Walker, The Kelvin-Helmholtz instability in the low-latitude boundary layer. Planet. Space Sci. 29, 1119 (1981)

C.E.J. Watt, R. Rankin, I.J. Rae, D.M. Wright, Inertial Alfvén waves and acceleration of electrons in nonuniform magnetic fields. Geophys. Res. Lett. 33, L02106 (2006). https://doi.org/10.1029/2005GL024779

D.E. Wendel, G.V. Khazanov, A.K. Tripathi, R.P. Singhal, E. Zesta, Source of the bursty bulk flow diffuse aurora: electrostatic cyclotron harmonic and whistler waves in the coupling of bursty bulk flows to auroral precipitation. J. Geophys. Res. Space Phys. 124, 6669-6690 (2019). https://doi.org/10.1029/ 2019JA026606

J.M. Weygand, M.G. Kivelson, H.U. Frey, J.V. Rodriguez, V. Angelopoulos, R. Redmon et al., An interpretation of spacecraft and ground based observations of multiple omega band events. J. Atmos. Sol.-Terr. Phys. 133, 185-204 (2015). https://doi.org/10.1016/j.jastp.2015.08.014

J.A. Wild, T.K. Yeoman, P. Eglitis, H.J. Opgenoorth, Multi-instrument observations of the electric and magnetic field structure of omega bands. Ann. Geophys. 18, 99-110 (2000). https://doi.org/10.1007/ s00585-000-0099-6

J.A. Wild, E.E. Woodfield, E. Donovan, R.C. Fear, A. Grocott, M. Lester et al., Midnight sector observations of auroral omega bands. J. Geophys. Res. Space Phys. 116(A5) (2011). https://doi.org/10.1029/ 2010ja015874

M. Wiltberger, V. Merkin, J.G. Lyon, S. Ohtani, High-resolution global magnetohydrodynamic simulation of bursty bulk flows. J. Geophys. Res. Space Phys. 120 (2015). https://doi.org/10.1002/2015JA021080

X. Xing, L. Lyons, Y. Nishimura, V. Angelopoulos, D. Larson, C. Carlson, J. Bonnell, U. Auster, Substorm onset by new plasma intrusion: THEMIS spacecraft observations. J. Geophys. Res. 115, A10246 (2010). https://doi.org/10.1029/2010JA015528

T. Yamamoto, Hybrid Kelvin-Helmholtz/Rayleigh-Taylor instability in the plasma sheet. J. Geophys. Res. 114, A06207 (2009). https://doi.org/10.1029/2008JA013760

T. Yamamoto, A numerical simulation for the omega band formation. J. Geophys. Res. Space Phys. 116, A2 (2011) 
T. Yamamoto, K. Makita, C.-I. Meng, A particle simulation of "giant" undulations on the evening diffuse auroral boundary. J. Geophys. Res. 98(A4), 5785-5800 (1993). https://doi.org/10.1029/92JA01434

T. Yamamoto, M. Ozaki, S. Inoue, K. Makita, C.-I. Meng, Convective generation of "giant" undulations on the evening diffuse auroral boundary. J. Geophys. Res. 99(A10), 19499-19512 (1994). https://doi.org/ 10.1029/94JA00273

J. Yang, F.R. Toffoletto, R.A. Wolf, S. Sazykin, RCM-E simulation of ion acceleration during an idealized plasma sheet bubble injection. J. Geophys. Res. 116, A05207 (2011). https://doi.org/10.1029/ 2010JA016346

J. Yang, F.R. Toffoletto, R.A. Wolf, S. Sazykin, On the contribution of plasma sheet bubbles to the storm time ring current. J. Geophys. Res. Space Phys. 120, 7416-7432 (2015). https://doi.org/10.1002/ 2015JA021398

Z.H. Yao et al., Conjugate observations of flow diversion in the magnetotail and auroral arc extension in the ionosphere. J. Geophys. Res. Space Phys. 118, 4811-4816 (2013). https://doi.org/10.1002/jgra.50419

C. Yue, Y. Nishimura, L.R. Lyons, V. Angelopoulos, E.F. Donovan, Q.Q. Shi, Z.H. Yao, J.W. Bonnell, Coordinated THEMIS spacecraft and all-sky imager observations of interplanetary shock effects on plasma sheet flow bursts, poleward boundary intensifications, and streamers. J. Geophys. Res. Space Phys. 118(6), 3346-3356 (2013)

E. Zesta et al., Ionospheric convection signatures of tail fast flows during substorms and Poleward Boundary Intensifications (PBI). Geophys. Res. Lett. 38 (2011). https://doi.org/10.1029/2011GL046758

E. Zesta, L.R. Lyons, E. Donovan, The auroral signature of earthward flow burst observed in the magnetotail. Geophys. Res. Lett. 27(20), 3241-3244 (2000). https://doi.org/10.1029/2000GL000027

E. Zesta, E. Donovan, L. Lyons, G. Enno, J.S. Murphree, L. Cogger, Two-dimensional structure of auroral poleward boundary intensifications. J. Geophys. Res. 107(A11), 1350 (2002). https://doi.org/ 10.1029/2001JA000260

E. Zesta, L. Lyons, C.-P. Wang, E. Donovan, H. Frey, T. Nagai, Auroral poleward boundary intensifications (PBIs): their two-dimensional structure and associated dynamics in the plasma sheet. J. Geophys. Res. 111, A05201 (2006). https://doi.org/10.1029/2004JA010640

Y. Zhang, L.J. Paxton, D. Morrison, A.T.Y. Lui, H. Kil, B. Wolven, C.-I. Meng, A.B. Christensen, Undulations on the equatorward edge of the diffuse proton aurora: TIMED/GUVI observations. J. Geophys. Res. 110, A08211 (2005). https://doi.org/10.1029/2004JA010668

M. Zhou et al., Cluster observations of kinetic structures and electron acceleration within a dynamic plasma bubble. J. Geophys. Res. Space Phys. 118, 674-684 (2013). https://doi.org/10.1029/2012JA018323

S. Zou et al., Identification of substorm onset location and preonset sequence using Reimei, THEMIS GBO, PFISR, and Geotail. J. Geophys. Res. Space Phys. 115 (2010). https://doi.org/10.1029/2010JA015520

Y. Zou, Y. Nishimura, L.R. Lyons, E.F. Donovan, J.M. Ruohoniemi, N. Nishitani, K.A. McWilliams, Statistical relationships between enhanced polar cap flows and PBIs. J. Geophys. Res. Space Phys. 119(1), 151-162 (2014) 